\title{
Effect of different surface active polysaccharide derivatives on the formation of ethyl cellulose particles by the emulsion- solvent evaporation method
}

\author{
Mojca Božič • Thomas Elschner • Doris Tkaučič • Matej Bračič • \\ Silvo Hribernik $\cdot$ Karin Stana Kleinschek $\cdot$ Rupert Kargl
}

Received: 27 March 2018/Accepted: 30 September 2018/Published online: 9 October 2018

(C) The Author(s) 2018

\begin{abstract}
This paper aims at a better understanding of the systematic production of the ethyl cellulose (EC) particles by using an emulsification-solvent evaporation method in the presence of different polysaccharide derivatives. In particular, the role of different surface active polymers i.e. one ioniccarboxymethyl cellulose, one nonionic-hydroxyethyl cellulose, and two amphiphilic-high molecular weight methyl cellulose and low molecular weight methyl cellulose on EC particle formation was investigated. We have established how individual surface active polysaccharides with varying concentration from 0.1 to $3.0 \mathrm{wt} \%$ affect particle size and its distribution, particle shape, surface charge, and
\end{abstract}

particle surface morphology. The interdependencies between surfactant nature and concentration at constant processing parameters and the subsequent nanoto micro-particle characteristics are discussed. It was determined that the particle size, surface morphology, supramolecular structure and surface properties of EC particles, prepared by an emulsion evaporation method can be effectively controlled by the type and concentration of used polysaccharide surfactant yielding spherical particles sizes from $170 \mathrm{~nm}$ to the micrometer level with smooth particle surfaces or remarkably a wrinkled surface morphology or "particle on particle" structures.

M. Božič $(\bowtie) \cdot$ T. Elschner · D. Tkaučič ·

M. Bračič · S. Hribernik · K. Stana Kleinschek · R. Kargl

Laboratory for Characterization and Processing of

Polymers (LCCP), Faculty of Mechanical Engineering, Institute for Engineering Materials and Design, University of Maribor, Smetanova ul. 17, 2000 Maribor, Slovenia e-mail: mojca.bozic@um.si

M. Božič · S. Hribernik · K. Stana Kleinschek · R. Kargl Faculty of Electrical Engineering and Computer Science, Institute of Automation, University of Maribor, Koroška cesta 46, 2000 Maribor, Slovenia

K. Stana Kleinschek · R. Kargl Institute for Chemistry and Technology of Materials (ICTM), Graz University of Technology, Stremayrgasse 9, 8010 Graz, Austria 


\section{Graphical abstract}

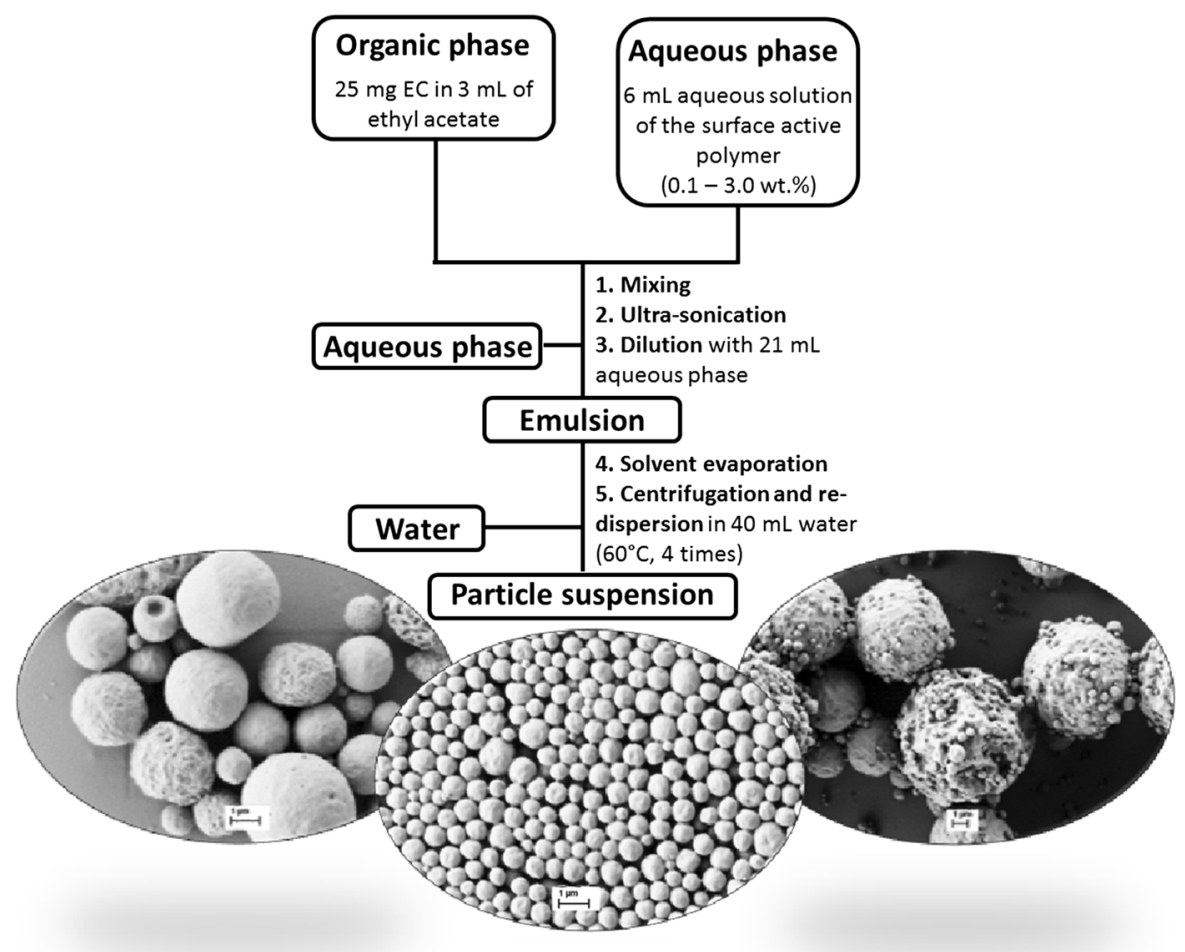

Keywords Ethyl cellulose nano/micro-particles . Emulsion method · Polyvinyl alcohol · Carboxymethyl cellulose $\cdot$ Hydroxyethyl cellulose $\cdot$ Methyl cellulose

\section{Introduction}

Ethyl cellulose (EC) is derived from a nearly inexhaustible natural polymeric material, cellulose, and possesses properties such as nontoxicity, chemical stability, compressibility, hydrophobicity, and low cost. The polymer has been widely used in various applications such as drug delivery systems (Katikaneni et al. 1995; Crowley et al. 2004), personal care products (Veeger et al. 2013; Bizmark and Ioannidis 2017), sensing systems (Generalova et al. 2009), etc. (Khan et al. 2006; Košak et al. 2015). Despite its wide usages in different pharmaceutical areas as a binder, as a bulk polymer for preparation of microcapsules and microspheres, as film-forming and matrix-forming material for sustained release dosage forms, etc. there is still significant research going on in regards to the EC exploitation for new pharmaceutical commercial applications (Rajabi-Siahboomi et al. 2017; Kulterer et al. 2012). In the recent years special attention was paid to design new methods for producing polysaccharide nanostructured assemblies that can possess properties that are significantly different from the bulk material (Christine and Ponchel 2017). Especially cellulosic based nanostructures, most often nanoparticles, exhibit a great potential as holders for imaging and drug agents because of their intrinsic physicochemical properties being biocompatible and biodegradable (Saravanakumar et al. 2012; Wondraczek et al. 2013).

Among the different processes, emulsification with subsequent solvent evaporation was the first method proposed (Vanderhoff et al. 1978) for the preparation of polymer nanoparticles and is today well established (Desgouilles et al. 2003; Wondraczek et al. 2013; Coombs Obrien et al. 2017). It is based on the nanoemulsification of an organic solution of a polymer in an aqueous phase followed by the evaporation of the 
organic solvent, leading to the precipitation of the polymer as nanoparticles of a few hundred nanometers in diameter. Most often the precipitated nanoparticles aggregate during and after their formation, therefore, liquid polymer droplets need surface active polymers i.e. surfactants, which covers the droplet with dense layers that provide steric hindrance to droplet coalescence. The kinetics of surfactant adsorption are governed by the interactions between dispersed droplets and the more or less covered interface, where the ultimate coverage of the organic solvent-water interface at steady state is controlled by the interactions among already adsorbed surfactants. Surfactant amount and nature have a substantial influence on the particle properties including size, size distribution, particle shape, surface charge, and particle surface morphology. For stabilizing the emulsion droplets during evaporation stage, different surfactants can be applied in order to enable the formation of nanoparticles from single emulsion droplet. Surfactants are usually incorporated in the aqueous phase and they are hydrophilic polymers, anionic or cationic surfactants. The most commonly reported surface active polymers for producing EC nanoparticles are: (1) low molecular weight surfactants: sodium dodecyl sulfate (Desgouilles et al. 2003; Urbán-Morlán et al. 2015) sorbitan monolaurate-Span 20 (Spernarth and Magdassi 2007), decaglycerol monolaurate (Spernarth and Magdassi 2007), lauryl ether (Wachsmann and Lamprecht 2015), cetyltrimethylammonium bromide (Wachsmann and Lamprecht 2015) and (2) polymer based surfactants: polyvinyl alcohol (PVA) (NavaArzaluz et al. 2012), polyethylene glycol sorbitan monolaurate-Tween 20 (Gunduz et al. 2012), (Wondraczek et al. 2013), polyoxyethylene (23) (Wachsmann and Lamprecht 2015), polysorbate 20 (Wachsmann and Lamprecht 2015), poloxamer 188 (El-Habashy et al. 2016), cremophor A25 (El-Habashy et al. 2016). Although already various different surfactants were tested in the EC nanoparticle preparation, to the best of our knowledge, the potential of ionic, nonionic and amphiphilic polysaccharide surfactants to design differently shaped EC nanoparticles were not investigated yet.

Polysaccharides present several advantages compared to the small molecules of surfactants: the viscosity of the medium is increased, and the thickness of the adsorbed layer at the interface is larger (as well as the van der Waals interactions), depending on the polysaccharides polymer structure and surface characteristics (Nasatto et al. 2014). Furthermore, the increasing interest for biocompatible and biodegradable materials makes polysaccharides even more attractive to be used as surfactants in medical applications, since a part of the surfactant remains on the particle surface even after extensive washing and alters biological activity of the final nanoparticles.

In this study, we applied a nano-emulsificationevaporation method to manufacture the $\mathrm{EC}$ nano to micro sized particles. EC was used as base polymer due to its high quantity accessibility in different qualities and its broad use in peroral and dermal applications. Ethyl acetate was used as water immiscible, volatile organic solvent with relatively low toxicity and as a stabilizing surfactant in water nonionic-amphiphilic polyvinyl alcohol (PVA) and different surface active polysaccharides; one ionic, one nonionic and two amphiphilic (i.e. carboxymethyl cellulose (CMC), hydroxyethyl cellulose (HEC), high molecular weight methyl cellulose and low molecular weight methyl cellulose (MC-HMw and MC-LMw, respectively) were examined. To control particle properties, the nano-emulsion template was regulated by adapting the concentration of the surface active polysaccharides. Newly produced EC nano to micro sized particles were characterized by dynamic light scattering (hydrodynamic radius and zeta potential for stability). Particle surface morphology was evaluated by field emission scanning electron microscopy (FESEM). Our findings contribute to the fundamental understanding of colloidal systems and inform about the control of EC nano- to micro-particle morphologies and composition, in particular by using different surface active polysaccharides as stabilizing surfactants.

\section{Materials and methods}

\section{Materials}

Following polysaccharides were used: Ethyl cellulose (EC) with molecular weight (Mw) of $26,700 \mathrm{Da}$ and average degree of substitution (DS) of 2.47; Sodium carboxymethyl cellulose (CMC) with $\mathrm{Mw}$ of 90,000 Da and DS of 0.7; Hydroxyethyl cellulose (HEC) with Mw of 380,000 Da and DS of 1.0; Methyl cellulose (MC-HMw) with Mw of 310,000 Da and DS 
of 1.8 and Methyl cellulose (MC-LMw) with Mw of $17,000 \mathrm{Da}$ and DS of 1.8. Polyvinyl alcohol (PVA) with $\mathrm{Mw}$ between 85,000-124,000 was used. All polymers were purchased from Sigma Aldrich Slovenia and used without further purification. Other reagents used were of analytical grade.

\section{Viscosity measurements}

All aqueous solution of the surface active polymer (i.e. CMC, HEC, PVA, MC-HMw and MC-LMw) at varying concentrations of $0.1,1.0$, and $3.0 \mathrm{wt} \%$ prior to particle synthesis were characterized in terms of their viscosity by means of a rotational viscometer (Fungilab) at room temperature i.e. $23 \pm 2{ }^{\circ} \mathrm{C}$. Each experiment was repeated three times and a standard deviation was calculated.

\section{Surface tension measurements}

Surface tension of the aqueous solution of the surface active polymer (i.e. CMC, HEC, PVA, MC-HMw and $\mathrm{MC}-\mathrm{LMw}$ ) at varying concentrations of $0.1,0.5,1.0$, 2.0 and $3.0 \mathrm{wt} \%$. was measured with a surface tensiometer (Kruss GmbH, Hamburg Germany), at a room temperature of $23 \pm 2{ }^{\circ} \mathrm{C}$. The tensiometer, which is equipped with a Wilhelmy plate $\left(10 \times 20 \mathrm{~mm}^{2}\right)$ of roughened platinum, was calibrated with distilled water $(\sigma=72.8 \mathrm{mN} / \mathrm{m})$. Measurements were repeated three times for every sample and in one repeat ten measurements were made.

Preparation of ethyl cellulose particle by emulsification-evaporation preparation method

A modified emulsification-evaporation method, as described previously in literature (Wondraczek et al. 2013), was used to manufacture the EC particles (Fig. 1). Briefly, $25 \mathrm{mg}$ of EC in $3 \mathrm{~mL}$ of ethyl acetate was slowly added to $6 \mathrm{~mL}$ of an aqueous solution of the surface active polymer (i.e. PVA, CMC, HEC, $\mathrm{MC}-\mathrm{HMw}$ and $\mathrm{MC}-\mathrm{LMw}$ ) at varying concentrations of $0.1,1.0$, and $3.0 \mathrm{wt} \%$ and stirred at $200 \mathrm{rpm}$ until a homogeneous solution was obtained (between 2 and $5 \mathrm{~h}$ depending on used surface active polymer). The mixture was further emulsified by pulse ultra-sonication ( $1 \mathrm{~s}$ on/2 s pause) using a Sonics VCX750 ultrasonic processor at $80 \%$ amplitude for $30 \mathrm{~s}$ at room temperature. The obtained emulsion was diluted

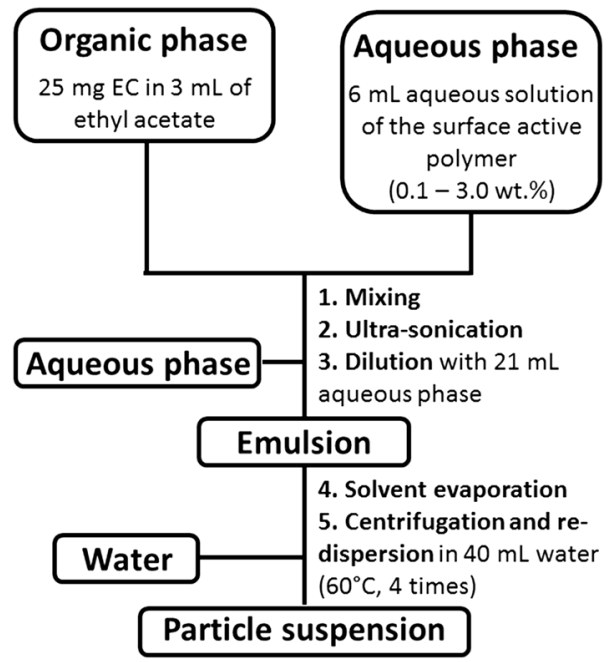

Fig. 1 Flow diagram of the preparation of EC particles

with $21 \mathrm{~mL}$ of the individual aqueous surface active polymer solution. The final particle solution was obtained by continuous stirring at $23 \pm 2{ }^{\circ} \mathrm{C}$ overnight or until the ethyl acetate was completely removed through evaporation. The excess of the surface active polymer was removed by centrifugation and re-dispersion in $40 \mathrm{~mL}$ of water at $60{ }^{\circ} \mathrm{C}$. The final rinsing step was repeated 4 times.

Field emission scanning electron microscopy (FESEM) measurements

The FE-SEM images of the particles were recorded with a Carl Zeiss FE-SEM SUPRA 35 VP electron microscope. For all samples, imaging was performed in high vacuum at $1 \mathrm{kV}$ accelerating voltage. The particle dispersions were placed on a conductive carbon adhesive tape, mounted on an aluminum sample holder, and air dried. In order to get high contrast images, the particles were coated with a sputtered layer of palladium. This of course can lead to some systematic error in the size measurements. According to the Eaton et al. (2017), the thickness of this layer would not be the same all over the sample, and will depend on the angle between the target and the part of the sample to be imaged. In particular, in the case of spherical particles, where the diameter of the observed particles is measured, a thinner layer deposit on a horizontally oriented surface, would be expected. Fourteen nanometers would be the maximum dilation of a measured particle that could possibly occur, if the 
sample was completely covered even on vertical surfaces. In this case the diameter measurement would measure the thickness of the layer twice, once on each side of the particle. Thus, there was likely an error of somewhere between 1 and $14 \mathrm{~nm}$ in these measurements due to coating.

Dynamic light scattering (DLS) and zeta potential

The $\mathrm{pH}$ dependent $\zeta$-potential and hydrodynamic diameter of the particle dispersions (ca. $0.1 \mathrm{wt} \%$ ) were determined by means of dynamic light scattering using a Zetasizer Nano ZS device (Malvern Instruments Ltd, United Kingdom, wavelength: $633 \mathrm{~nm}$, scattering angle: $173^{\circ}$ ). A field of $40 \mathrm{~V}$ was applied across the nominal electrode spacing of $16 \mathrm{~mm}$. Prior to the measurements, particle dispersions were sonicated for $60 \mathrm{~s}$ by pulse sonication ( $1 \mathrm{~s}$ on/ $2 \mathrm{~s}$ off $)$ with an amplitude of $30 \%$. The dynamic light scattering and zeta potential measurements were conducted at $22{ }^{\circ} \mathrm{C}$. Mean particle diameters were approximated as the effective (Z-average) diameters from the bimodal size distribution. The $\mathrm{pH}$ dependent measurements were conducted in a $\mathrm{pH}$ range from $10<\mathrm{pH}<2$ by using $0.1 \mathrm{M} \mathrm{NaOH}$ and $0.1 \mathrm{M} \mathrm{HCl}$.

A spherical particle's size was determined by relating the translational diffusion coefficient, $D_{t}$ to particle diameter, and $d_{H}$ with the Stokes-Einstein relationship:

$\mathrm{D}_{\mathrm{t}}=\frac{k T}{3 \pi \eta d_{H}}$

where $k$ is the Boltzmann's constant, $T$ is the absolute temperature, and $\eta$ is the viscosity of the suspending medium. The Stokes-Einstein equation is applied for non-interacting spherically shaped particles.(Božič et al. 2015)

Attenuated total reflectance fourier transform infrared spectroscopy (ATR-FTIR) measurements

Before ATR-FTIR measurements the EC particle samples were freeze-dried to remove bound water. ATR-FTIR spectra were recorded using a PerkinElmer Spectrum One FTIR spectrometer with a Golden Gate ATR attachment and a diamond crystal at room temperature i.e. $23 \pm 2{ }^{\circ} \mathrm{C}$. The absorbance measurements were carried out within the $3100-3700 \mathrm{~cm}^{-1}$, with 16 scans and a resolution of
$4 \mathrm{~cm}^{-1}$. The resolution of the spectra was improved by their deconvolution from a background scattering using a Gaussian function curve-fitting analysis in order to quantify the intensities and the band positions. All the data analyses were performed using the PeakFit software version 4.12.

The energy of hydrogen bonds $\left(\mathrm{E}_{\mathrm{H}}, \mathrm{kJ}\right)$ was calculated with following equation:

$E_{H}=\frac{1}{K}\left(\frac{v_{0}-v}{v_{0}}\right)$

where $v_{0}$ is the frequency corresponding to the free $\mathrm{OH}$ groups $\left(\mathrm{cm}^{-1}\right), v$ is frequency of the bonded $\mathrm{OH}$ groups $\left(\mathrm{cm}^{-1}\right)$, and $K$ is constant $1.68 \times 10^{-2} \mathrm{kcal}^{-1}$ (Petreus et al. 2003; Ciolacu et al. 2011).

The intra- and intermolecular hydrogen bonds bond distance $(\mathrm{R})$ was calculated with following equation:

$\Delta v=4.43 \times 10^{3}(2.84-R)$

where $\Delta v$ is the frequency shift of the $\mathrm{OH}$ absorption band caused by hydrogen bonding (Pimentel and Sederholm 1956).

\section{Results and discussion}

Viscosity measurements of the surface active polymer solutions

The utilization of surface active polysaccharides to form liquid polymer droplets may be influenced by the viscosity of their solutions. If the viscosity is too high, it can lead to a less favorable mixing efficiency and thus, to particle size increase. For these reasons, we measured the impact of the polymer nature and its concentration on the viscosity of aqueous solution. Following polymers have been studied: PVA, CMC, HEC, MC-LMw, and MC-HMw (Fig. 2). As the concentration increases, the random coils begin to overlap and a considerable increase in viscosity is observed as the chains interact with each other. A very sharp increase in viscosity up to $31,261.0 \mathrm{cP}$ and $15,265.5 \mathrm{cP}$ at concentrations of $3 \mathrm{wt} \%$ is observed for nonionic $\mathrm{HEC}$ and amphiphilic $\mathrm{MC}-\mathrm{HMw}$, respectively. HEC and MC-HMw are high molecular weight cellulose ethers of 380,000 and $310,000 \mathrm{~g} / \mathrm{mol}$, respectively, where at higher concentrations the interaction between chains with hydrophobic moieties 


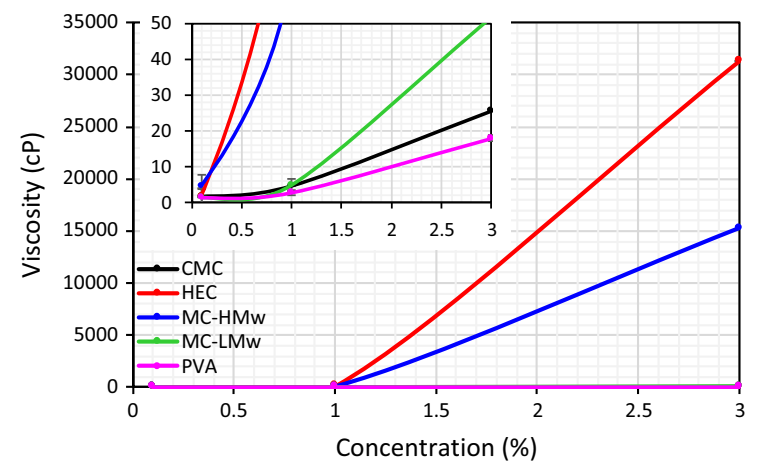

Fig. 2 Viscosity of aqueous PVA, CMC, HEC, MC-LMw, and $\mathrm{MC}-\mathrm{HMw}$ solutions at weight concentrations of $0.1,1.0$ and $3.0 \mathrm{wt} \%$

i.e. $-\mathrm{CH}_{2} \mathrm{CH}_{2} \mathrm{OH}$ and $-\mathrm{CH}_{3}$, respectively, are amplified. On the other hand, anionic CMC with relatively high molecular weight of $90000 \mathrm{~g} / \mathrm{mol}$ at concentrations of $3 \mathrm{wt} \%$ reaches a viscosity of only $25.6 \mathrm{cP}$. In the $\mathrm{CMC}$ the $\mathrm{OH}$ groups are substituted by $\mathrm{CH}_{2-}$ COONa, (carboxymethyl groups), which gives the $\mathrm{CMC}$ the polyelectrolyte character. The main cause of lower values of the viscosity is ascribed to the conformational change of the main chain due to the electrostatic repulsive forces between the charged groups. The viscosity of the aqueous solution of MCLMw with molecular weight of $7000 \mathrm{~g} / \mathrm{mol}$ was 51.7 $\mathrm{cP}$ at $3 \mathrm{wt} \%$, which is 295 times lower compared to MC-HMc with a molecular weight of $310000 \mathrm{~g} / \mathrm{mol}$. Because of their conformation in solution, polysaccharides in the aqueous solvent take up more space i.e. the larger the molecules, the larger is the hydrodynamic volume. Therefore, higher molecular weight polysaccharide based solutions have a higher viscosity at the same concentration. PVA, a water soluble synthetic polymer, is one the most commonly used emulsifier in the formulation of EC particles since it forms particles of relatively small size and uniform size distribution. PVA viscosity at $3 \mathrm{wt} \%$ was $17.9 \mathrm{cP}$, the lowest compared to all measured polysaccharides.

Surface tension $(\sigma)$ measurements of the surface active polymer solutions

One of the most useful properties of surface active polysaccharides is their capacity to lower the interfacial tension of their solvents, which results in a significant reduction in the energy required during emulsification. The amphiphilic character, due to the presence of hydroxyethyl (hydrophobic part) and hydroxyl groups or carboxyl (hydrophilic part) in the chains, means that polysaccharides can be adsorbed and oriented at liquid-liquid interfaces to reduce efficiently the interfacial tension and to promote the formation of a nanoparticle dispersion system. In order to investigate the surface activity of polysaccharides and PVA, the surface tension of the aqueous phases used in the emulsification-evaporation method was measured. Figure 3 shows the surface tension $(\sigma)$ of aqueous PVA, CMC, HEC, MC L-Mw, and MC $\mathrm{H}-\mathrm{Mw}$ solutions at weight concentrations of $0.1,0.5$, $1.0,2.0$ and $3.0 \mathrm{wt} \%$. The $\sigma$ of water at the air interface is $72.87 \mathrm{mN} / \mathrm{m}$. With the progressive addition of MC-LMw, MC-HMw and PVA, $\sigma$ starts to decrease over 0.1 to $1.0 \mathrm{wt} \%$ up to the critical aggregation concentration (CAC), being $0.5 \mathrm{wt} \%$ for PVA and $1.0 \mathrm{wt} \%$ for MC-LMw and MC-HMw. Decrease of $\sigma$ is related to the progressive loading of surfactant molecules at the interface with the orientation of hydrophobic blocks. Above a concentration of $1.0 \mathrm{wt} \%$ surface tension started to increase for all three surfactants. At concentration of $0.5 \mathrm{wt} \%$ of PVA and $1.0 \mathrm{wt} \%$ of MC-LMw and MC-HMw the energy of the water surface is the lowest and, thus it is expected that these concentrations will provide optimal emulsification between formed EC particles and water.

Particle size, distribution and particle surface morphology comparing FE-SEM and DLS results

Representative FE-SEM micrographs of EC particles prepared without and in the presence of surface active

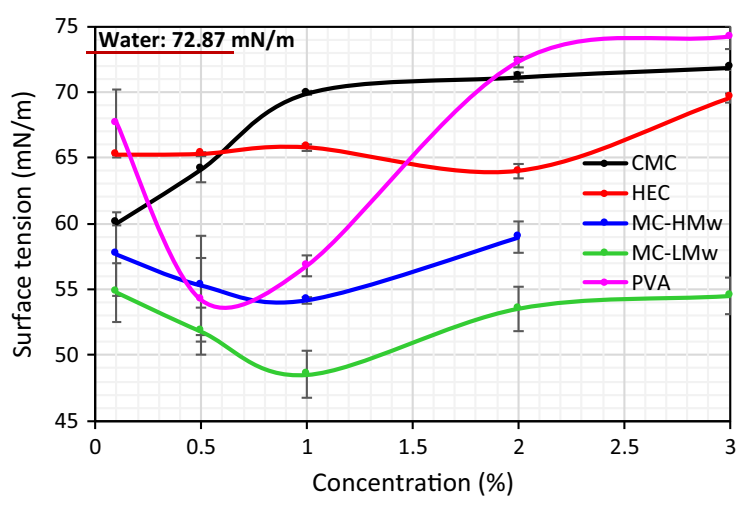

Fig. 3 Surface tension of aqueous PVA, CMC, HEC, MCLMw, and MC-HMw solutions at weight concentrations of 0.1 , $0.5,1.0,2.0$ and $3.0 \mathrm{wt} \%$ 
polymers at different concentrations are presented in Figs. 4, 5, 6, 7, 8 and 9 along with results of size distribution analysis in wet and dry state. Dry particles size was derived by processing SEM images with ImageJ program, whereas wet particle size was measured by DLS. Detailed analysis of reference EC particles using FE-SEM revealed that when only EC was used without the presence of surface active polymers, near-spherical, polydisperse particles with a smooth outer surface ranging from 200 to $1800 \mathrm{~nm}$ diameter in the dry state were produced (Fig. 4). During evaporation, emulsion droplet coalescence occurred prior to obtaining stable and solvent-free particles, making the particles stick together in a polymer matrix as shown in Fig. 4. The wet-state hydrodynamic diameter detected with DLS ranges from 288 to $2288 \mathrm{~nm}$, which deviates from the diameter of the dried particles. This can be attributed to the fact that EC can take up water, although is water insoluble polymer. EC in water medium swells depending on the number of ethyl groups in the cellulose chain and on the hydrogen bonding potential with water attributable to the polarity difference between the oxygen atom and the ethyl group of EC. Swelling of EC particles is a process, which is accompanied by increase of diameter due to solvent i.e. water molecules penetration into particles. The fact that light scattering is actually measuring the hydrodynamic radii of the particles, which includes not just the particle itself, but the ionic and solvent layers associated with it in solution, under the particular measurement conditions, we can estimate that the EC particle diameter increases from 27 to $40 \%$ after exposure to water.
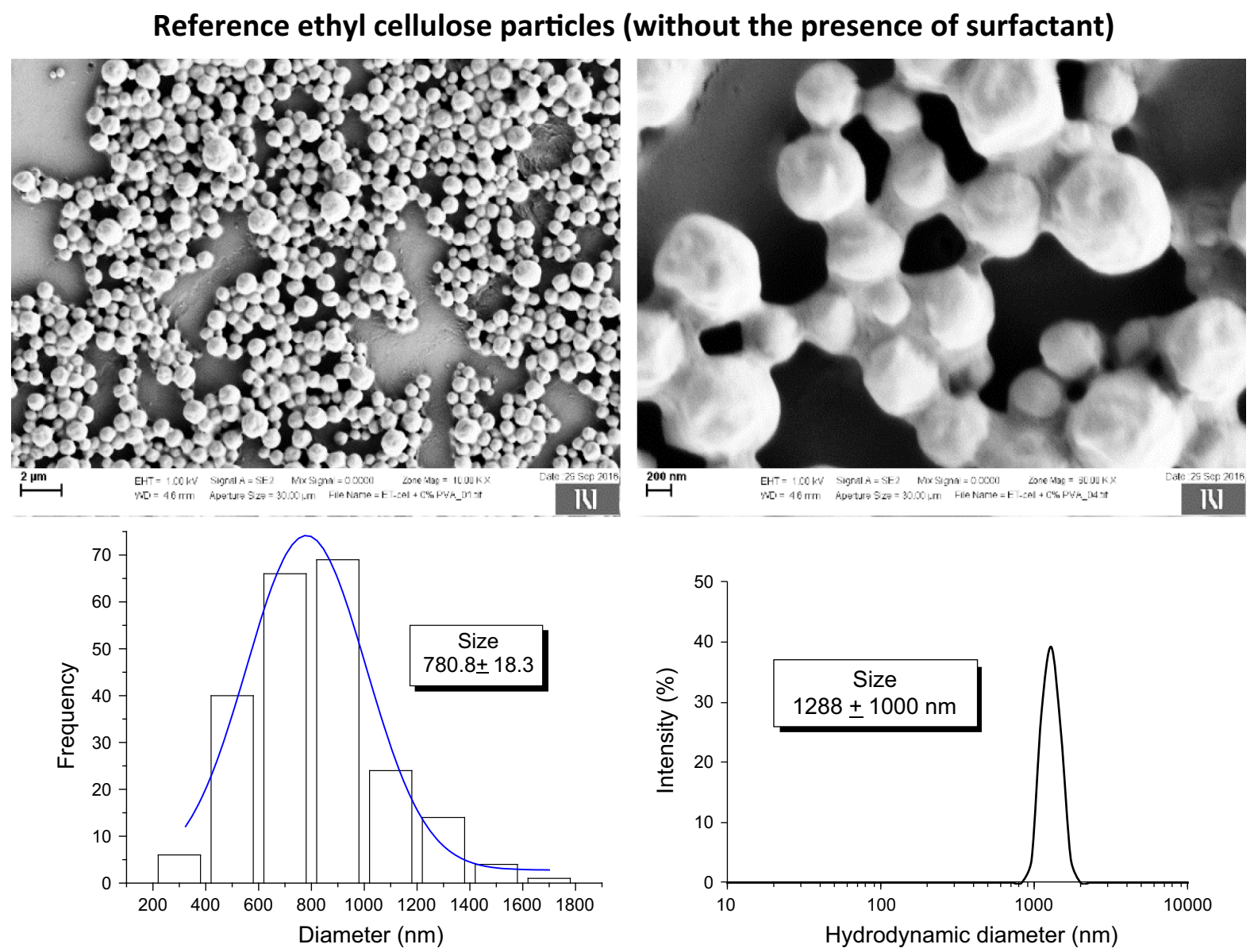

Fig. 4 FE-SEM images of reference EC particles without the presence of surface active polymer along with their particle size distribution and hydrodynamic particle diameter in water 


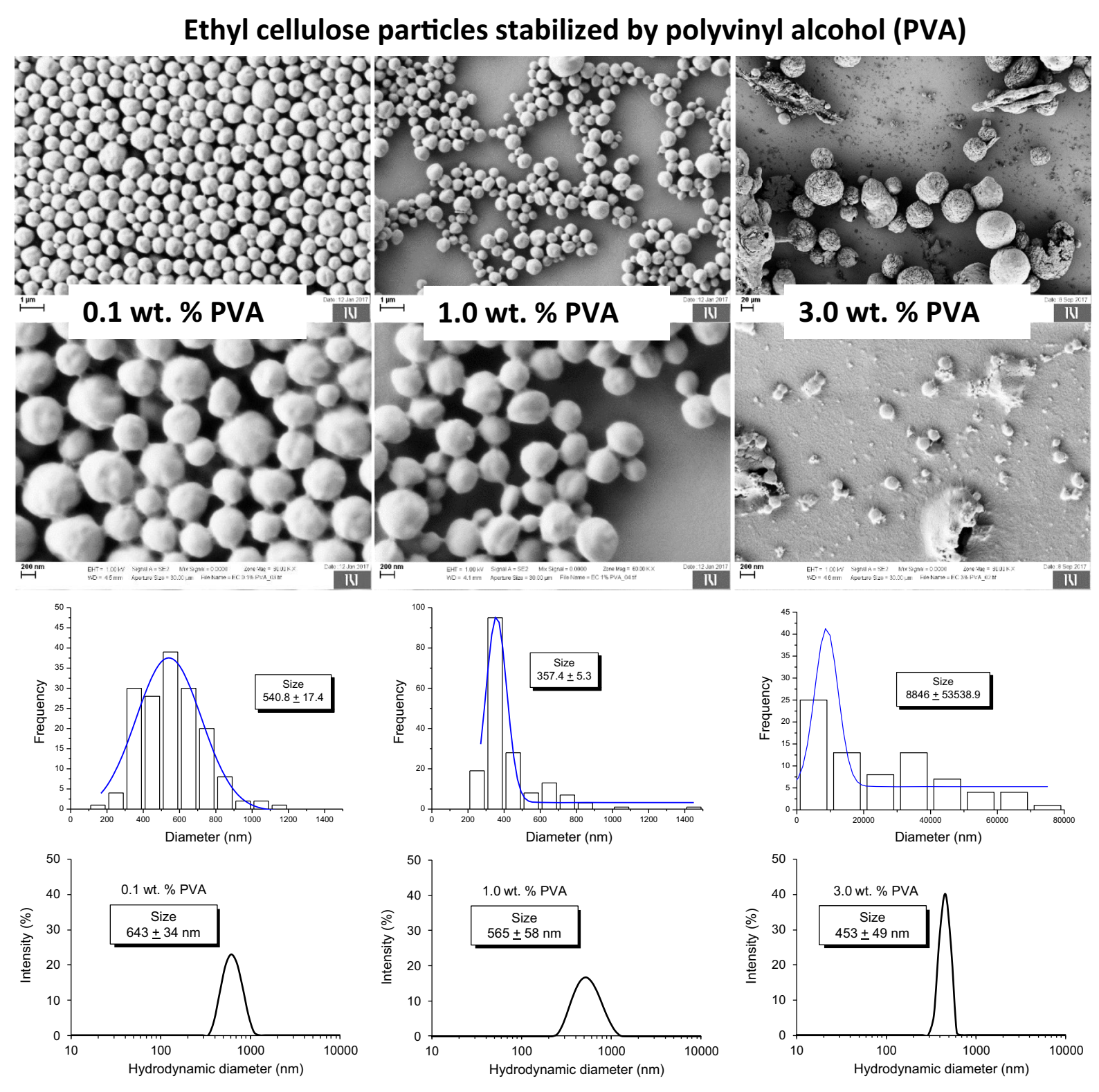

Fig. 5 FE-SEM images of EC particles prepared by emulsion evaporation method in the presence of PVA at weight concentrations of $0.1,1.0$ and $3.0 \mathrm{wt} \%$ along with their particle size distribution and hydrodynamic particle diameter in water

\section{EC particles, stabilized by the PVA}

Figure 5 shows FE-SEM images of EC particles prepared in the presence of PVA at weight concentrations of $0.1,1.0$ and $3.0 \mathrm{wt} \%$ along with their particle size distribution analysis and hydrodynamic particle diameter in water. It is shown that EC prepared in the presence of PVA at weight concentrations of 0.1 and $1.0 \mathrm{wt} \%$ are spherical with a smooth surface in the dried-state, whereas the EC particles in the presence of $3.0 \mathrm{wt} \%$ PVA are random ranging from nano to micro sizes and spherical to non-spherical shapes i.e. nonparticle matter. Results are in good agreement with the surface tension measurements on aqueous PVA solutions where the energy of water surface was the lowest between 0.1 and $1.0 \mathrm{wt} \%$ of PVA. The amphiphilic character, due to the presence of methylene groups (hydrophobic part) and hydroxyl groups (hydrophilic 


\section{Ethyl cellulose particles stabilized by carboxymethyl cellulose (CMC)}
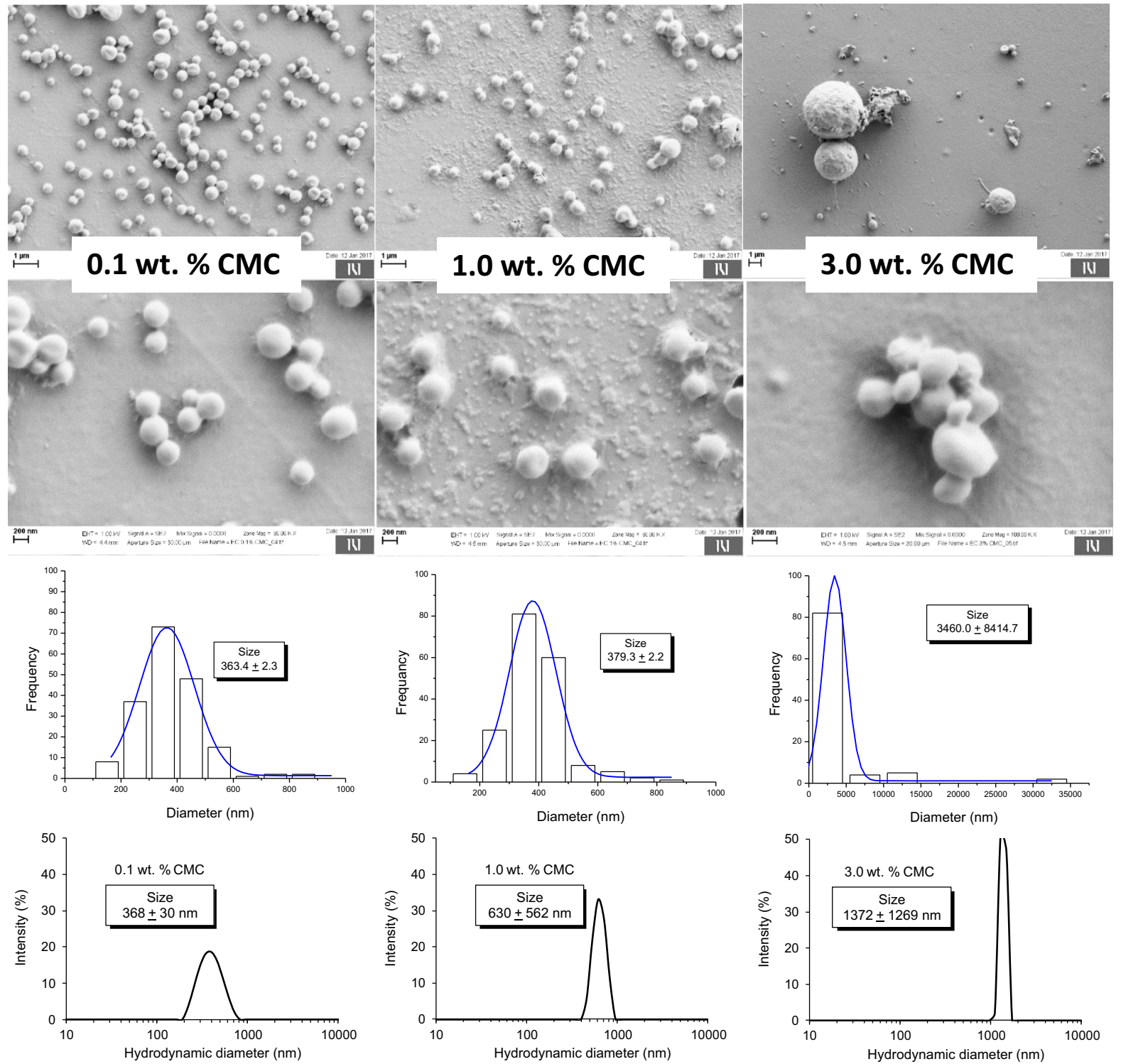

Fig. 6 FE-SEM images of EC particles prepared by emulsion evaporation method in the presence of CMC at weight concentrations of $0.1,1.0$ and $3.0 \mathrm{wt} \%$ along with their particle size distribution and hydrodynamic particle diameter, in water

part) in the chains, means that PVA can be adsorbed and oriented at liquid-liquid interfaces to reduce efficiently the interfacial tension and to promote the formation of a dispersed system. On the other hand, with increasing the PVA concentration to $3.0 \mathrm{wt} \%$ surface tension increased above the water surface tension (i.e. $72.87 \mathrm{mN} / \mathrm{m}$ ), thus, the interfacial energy between formed EC was too high and emulsion droplet coalescence occurred. The average sizes of the dried
EC particles produced at $0.1,1.0$ and $3.0 \mathrm{wt} \%$ of PVA are $540 \pm 17,357 \pm 5$ and $8846 \pm 53,538 \mathrm{~nm}$. The average size and size distribution decreases from 0.1 to $1.0 \mathrm{wt} \%$ and increases at $1.0 \mathrm{wt} \%$ PVA. Based on the visual analysis of the SEM images, it is possible to form spherical dried EC with average sizes of approximately from 350 to $540 \mathrm{~nm}$ by adjusting the PVA concentration. Particles still seem to be attached to each other after drying with thin PVA or ethyl 


\section{Ethyl cellulose particles stabilized by Hydroxyethyl cellulose (HEC)}

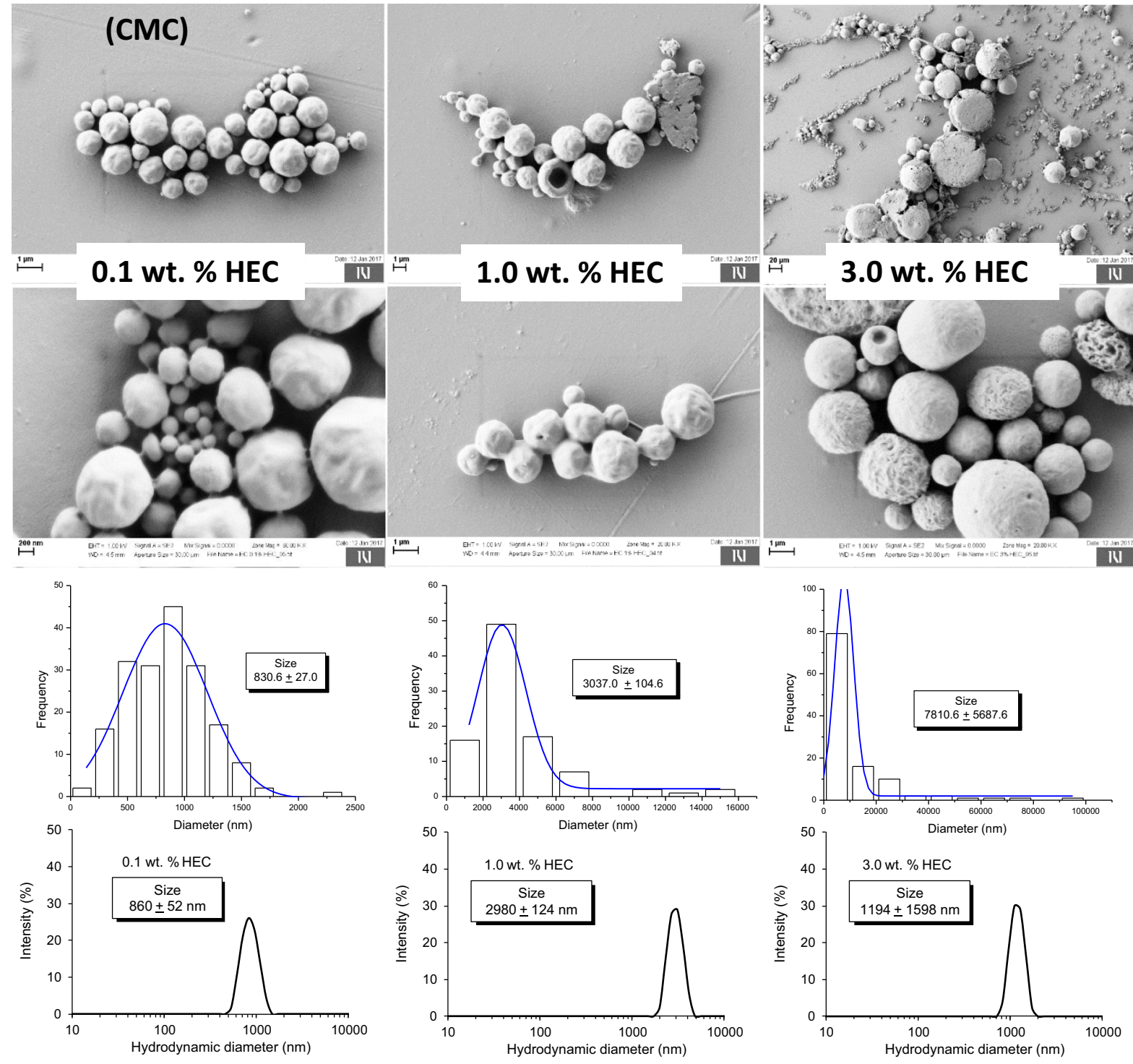

Fig. 7 FE-SEM images of EC particles prepared by emulsion evaporation method in the presence of HEC at weight concentrations of $0.1,1.0$ and $3.0 \mathrm{wt} \%$ along with their particle size distribution and hydrodynamic particle diameter in water

cellulose bridge. Taking into account the swelling degree, the particle sizes obtained at 0.1 and $1.0 \mathrm{wt} \%$ PVA are fairly similar to those detected by DLS. The average swelling degree for EC particles produced at 0.1 and $1.0 \mathrm{wt} \%$ PVA were 19 and $58 \%$, respectively. On the other hand, the DLS sizes of EC particles produced at $3.0 \mathrm{wt} \%$ PVA cannot be directly compared to dried sizes. DLS is a dynamic measurement, extremely sensitive to the dispersion/aggregation behavior of the particles in solution and because larger particles sediment faster than smaller under the influence of gravitation during the measurement itself, the larger sizes are excluded from results. Results confirm that this technique is not useful for characterization of samples with large particle size distribution.

EC particles, stabilized by the CMC

Based on the visual analysis of the FE-SEM images (Fig. 6), it is possible to form spherical dried EC 


\section{Ethyl cellulose particles stabilized by methyl cellulose (MC-HMw)}
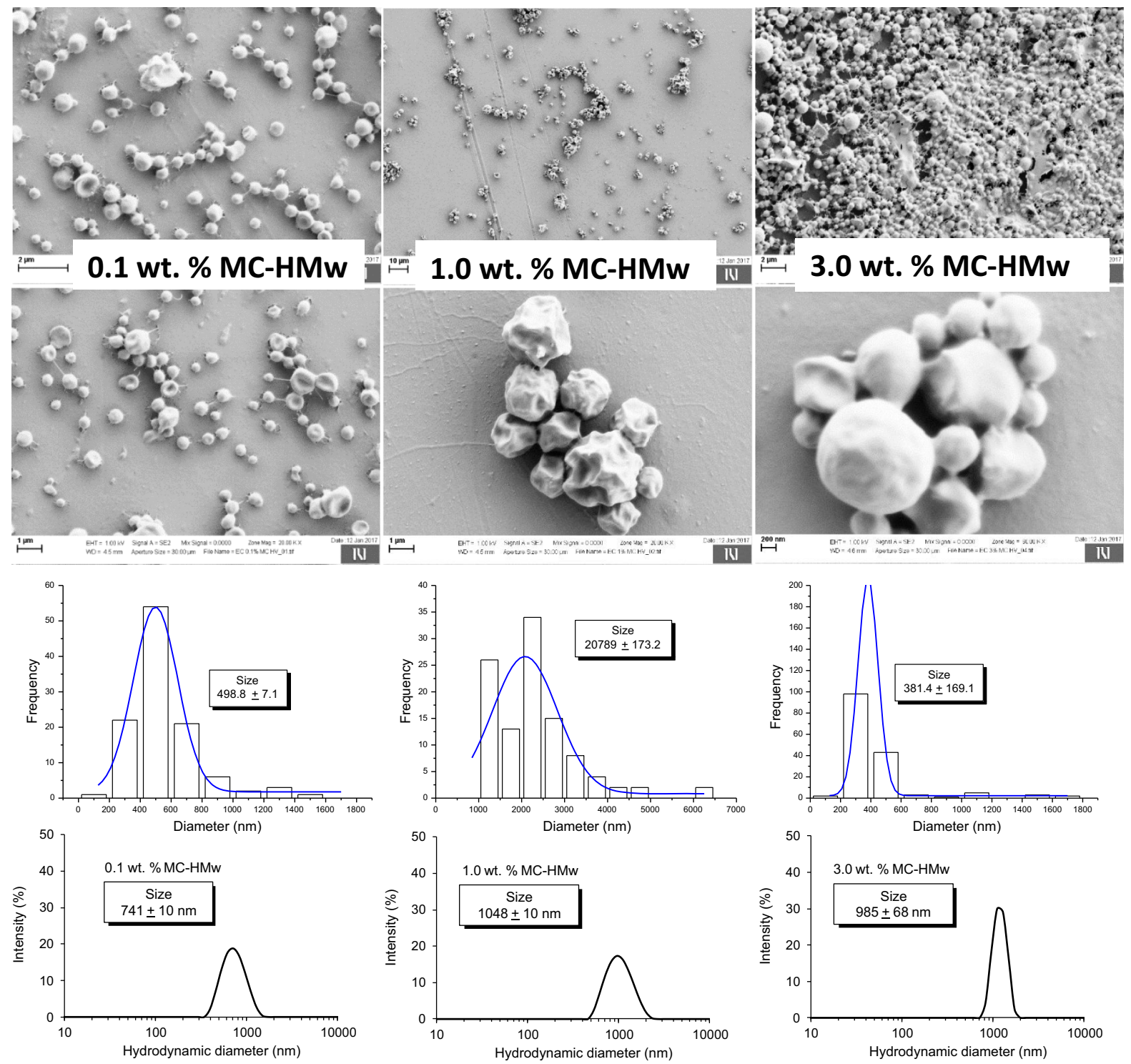

Fig. 8 FE-SEM images of EC particles prepared in the presence of MC-HMw at weight concentrations of $0.1,1.0$ and $3.0 \mathrm{wt} \%$ along with their particle size distribution and hydrodynamic particle diameter in in water

particles in the presence of CMC with average sizes of approximately 360 and $3500 \mathrm{~nm}$ by adjusting the CMC concentration from 0.1 to $3.0 \mathrm{wt} \%$, respectively. As expected from surface tension results, the best formulated EC particles were obtained at the used concentration of $0.1 \mathrm{wt} \%$. By increasing the concentration of CMC, surface tension increased, resulting in increased interfacial tension and poor formation of EC particles. CMC differs from other tested polysaccharide derivatives with hydrophobic moieties in surface charge i.e. $\mathrm{OH}$ groups are substituted with carboxymethyl groups, transforming polymer into an anionic polyelectrolyte (Kargl et al. 2012). The $\mathrm{CH}_{2} \mathrm{COONa}$ group causes a loss of the possibility of parallel association of $\mathrm{CMC}$ chains in sheet-like structures (a characteristic of the cellulose structure leading to supramolecular organization in microfibrils) because of both steric hindrance and electrostatic 


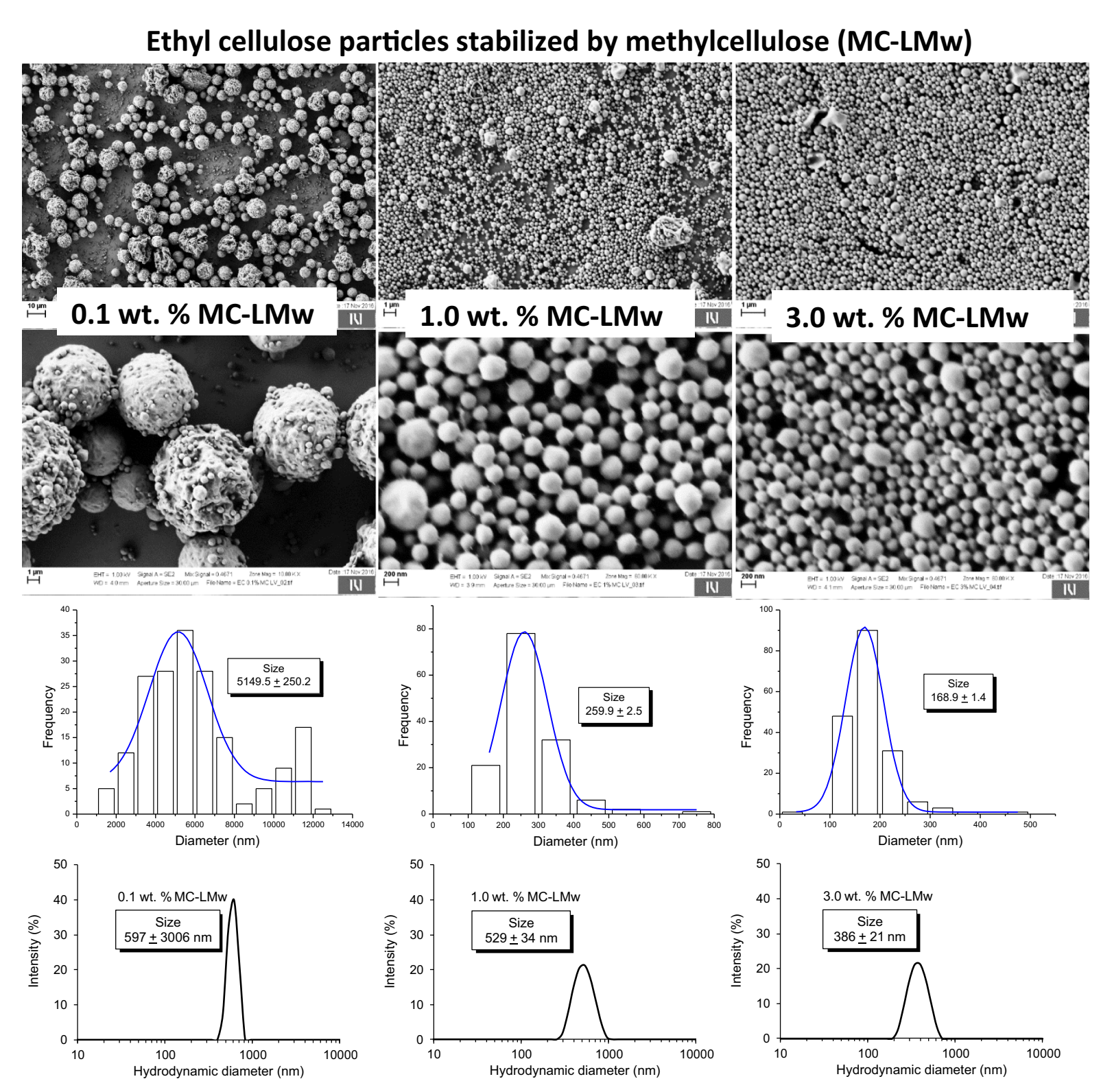

Fig. 9 FE-SEM images of EC particles prepared in the presence of MC-LMw at weight concentrations of 0.1, 1.0 and $3.0 \mathrm{wt} \%$ along with their particle size distribution and hydrodynamic particle diameter in water

repulsion. In aqueous systems at low CMC concentration, polymer chain adopts an expanded conformation in order to minimize the electrostatic repulsion between the carboxylated groups carried by the polymer segments (Mohan et al. 2015). However, as the polymer concentration increases, the excluded volume effect of a chain becomes progressively screened and the expansion of the chains decreases to give an ideal dimension. In the range of
1.0-3.0 wt \% the intermolecular interactions of CMC are significantly increased and have negative effect of the formation of EC particles. At 1.0 and $3.0 \mathrm{wt} \%$ $\mathrm{CMC}$ also, some non-particle matter is detected that may be dried CMC.

The average swelling degree for EC particles produced at 0.1 and $1.0 \mathrm{wt} \%$ of CMC were 1 and $66 \%$, respectively. On the other hand, the DLS sizes of EC particles produced at $3.0 \mathrm{wt} \%$ of CMC are not 
comparable in the case of larger particles as already explained.

\section{EC particles, stabilized by the HEC}

The ability of nonionic hydroxyethyl cellulose (HEC) to promote formation of EC particles is shown on FESEM images in Fig. 7. Images show that EC particles formed during emulsification evaporation method in the presence of $0.1 \mathrm{wt} \%$ of HEC have similar sizes as the reference EC particles without the presence of any surfactant. This was expected regarding to surface tension measurements, where HEC did not lower the surface tension of aqueous solutions. Spherical entities with a size ranging between 800 and $860 \mathrm{~nm}$ of diameter were produced. A difference is found in the formation of separated particles in the presence of HEC compared to reference EC particles with excess of free polymer matrix as shown in Fig. 4. Also the particle swelling is decreased from 65 to $3 \%$ indicating a fairly packed structure. It is assumed that the compact packing of chains resulting from interpenetration leads to formation of a rigid film at the droplet interface which resists shear and imparts mechanical stability to the emulsion droplets during emulsification. By increasing the HEC concentration to $3.0 \mathrm{wt} \%$ particle size diameter and particle distribution increased gradually (from $830 \mathrm{~nm}$ to $7.81 \mu \mathrm{m}$ ). Particles from spherical to non-spherical shapes with different surface morphology were formulated i.e. large amorphous polymer aggregates in addition to the particles. The used HEC is a high molecular weight polysaccharide of $380000 \mathrm{~g} / \mathrm{mol}$. At higher concentrations the interaction between chains with hydrophobic moieties i.e. $-\mathrm{CH}_{2} \mathrm{CH}_{2} \mathrm{OH}$ are amplified to viscosity up to $31,261.0 \mathrm{cP}$ at $3.0 \mathrm{wt} \%$ of HEC. When using high concentrations of surfactant there are two competitive effects; an enhanced interfacial stabilization that causes a particle size decrease and an increased viscosity of the aqueous phase, which can lead to a less favorable mixing efficiency and thus, to particle size increase. Usually, the concentration of used surfactant at which one effect starts dominating over the other depends on the system and processing parameters.
EC particles, stabilized by the $M C-H M w$

Figure 8 presents FE-SEM images of EC particles prepared in the presence of $\mathrm{MC}-\mathrm{HMw}$ at weight concentrations of $0.1,1.0$ and $3.0 \mathrm{wt} \%$ along with their particle size distribution and hydrodynamic particle diameter in water. Methyl cellulose (MC) with a medium degree of substitution (DS) is a watersoluble polymer that can lower the surface tension due to its intrinsic amphiphilic properties. These abilities strongly depend on the molecular weight as can be seen from Figs. 8 and 9, where effects of low and high molecular weight $\mathrm{MC}$ on the formation of $\mathrm{EC}$ particles are compared. By using high molecular weight-MC$\mathrm{HMw}(310,000 \mathrm{~g} / \mathrm{mol})$, the formation of spherical particles was hindered even at low concentration. Obtained EC particles at $0.1 \mathrm{wt} \% \mathrm{MC}-\mathrm{HMw}$ were spherical to plate like shape with average size of $500 \mathrm{~nm}$. Particles were bridged between themselves by free MC-HMw or EC polymer. With increasing the concentration to $1.0 \mathrm{wt} \%$ the particles size increased to average of $20 \mu \mathrm{m}$. The remarkable wrinkled surface morphology of the spherical particles was obtained only with EC-HMw at concentration of $1.0 \mathrm{wt} \%$. With increasing the concentration of $\mathrm{MC}-\mathrm{HMw}$, intermolecular aggregation occurred at a critical overlap concentration of MC-HMw, which led to the association of hydrophobic groups between different MC$\mathrm{HMw}$ molecules, and a transient three-dimensional network was formed. Hence the viscosity of the solution drastically increased. Unexpectedly, the EC particle size decreased to an average of $380 \mathrm{~nm}$ when MC-HMw concentration was increased to $3.0 \mathrm{wt} \%$. Although the extensive washing, a lot of MC-HMw polymer stayed firmly attached to EC particles. The DLS sizes of EC particles produced in the presence of $\mathrm{MC}-\mathrm{HMw}$ are not comparable due to dual mixture of nano to micro sized particles and large extent of free polymers.

\section{EC particles, stabilized by the MC-LMw}

Representative FE-SEM images of EC particles obtained in the presence of low molecular weight$\mathrm{MC}-\mathrm{LMw}$ at weight concentrations of $0.1,1.0$ and $3.0 \mathrm{wt} \%$ along with their particle size distribution and hydrodynamic diameter in in water are presented in Fig. 9. In the presence of $0.1 \mathrm{wt} \%$ of MC-LMw, average diameter of spherical particles varied from 4.9 
to $5.4 \mu \mathrm{m}$, while at $1.0 \mathrm{wt} \%$ it ranged from 257 to $262 \mathrm{~nm}$ and at $3.0 \mathrm{wt} \%$ from 167 to $170 \mathrm{~nm}$. Particles prepared in the presence of 0.1 to $3.0 \mathrm{wt} \% \mathrm{MC}-\mathrm{LMw}$ are spherical particles without any visible inter bonding. A very interesting surface morphologynanoparticles attached onto the micro particles-were obtained only at $0.1 \mathrm{wt} \% \mathrm{MC}-\mathrm{LMw}$. At this concentration, particles in the nanometer and micrometer ranges coexist, where nanometer particles are stuck on the surface of micrometer range particles. A reasonable assumption about the low concentration of MC$\mathrm{LMw}$ leading to the formation of large and small droplets and broad size distribution is that the low MCLMw concentration cannot produce higher viscosity or stabilize more interfaces. By increasing MC-LMw concentration in the aqueous phase results in more MC-LMw molecules being available for sterically stabilizing the more extended surfaces generated from the smaller emulsion droplets. In general, the higher MC-LMw concentration in the external aqueous phase, the smaller the mean particles size. We can conclude that at $3.0 \mathrm{wt} \%$ of MC-LMw the MC-LMw completely covered the EC-ethyl acetate droplets and firmly anchored at the interface, forming a thick film with optimal conformation of polymer chains in the external phase. It is recognized that the efficiency of the steric stabilization depends on the conformation adopted by the polymer chains at the interface which is governed by the number and the type of functional groups that constitute the polymer. For MCs, methyl groups are responsible for the conformation of the polymer at the organic solvent/water interface. These groups are anchored to the droplet surface and thus they determine the number and the length of loops and tails that will form during adsorption of the $\mathrm{MC}$ polymer chains. Consequently, the hydrated chain segments that extend into the continuous phase adopt a definite conformation to induce steric stabilization during emulsification. DLS was also used to characterize the dispersions from which the samples for FESEM were made. This technique is very different to imaging of dried samples, and is sensitive to dynamic aggregation, aggregation, agglomeration, etc. In the case of EC particles in the presence of $0.1 \mathrm{wt} \%$ of MCLMw, the DLS data are not comparable to the microscopic data due to sedimentation of larger particles, whereas in the case of 1.0 and $3.0 \mathrm{wt} \%$ $\mathrm{MC}-\mathrm{LMw}$ the nanoparticles agglomerate according to the zeta potential measurements (Fig. 9) and swelling degree could not be estimated.

$\zeta$-potential of EC particles

The $\mathrm{pH}$ dependent zeta potential curves for particles prepared with and without the presence of PVA, CMC, HEC, MC-HMw and MC-LMw at weight concentrations of $0.1 \mathrm{wt} \%, 1.0 \mathrm{wt} \%$, and $3.0 \mathrm{wt} \%$ are depicted in Fig. 10. The absolute value of $\zeta$-potential for reference EC particles (without the presence of any surfactant) increased gradually from $\mathrm{pH} 2$ to $\mathrm{pH} 6$ $(-1 \mathrm{mV}$ to $-50 \mathrm{mV})$ and remain constant $\mathrm{pH} 6$ to pH 10 (ca. $-50 \mathrm{mV}$ ). Dispersions possess good stability between $\mathrm{pH} 3$ and $\mathrm{pH} 10$. A negative $\zeta$ potential around $-50 \mathrm{mV}$ indicates the presence of a strong negative charge on the EC particle interface. There are two possibilities to explain the origin of this charge: it is either intrinsic, i.e. EC particles have a native negative charge stemming from the dissociation of ionic bonds, or it is apparent, i.e. induced by the solvent or dissolved ions bound to the interface.(Jin et al. 2012) Looking at the molecular structure of EC, it is difficult to foresee the origin of a native negative charge. Although, the cellulose starting material can be partially oxidized and some carboxylic groups can be present, the part of negative $\zeta$-potential can be due to an apparent negative charge, induced by the water molecules or the specific adsorption of $\mathrm{OH}^{-}$ions, which concentration increased by increasing the $\mathrm{pH}$ leading to more negative zeta potential. $\mathrm{OH}^{-}$ions adsorption is well known to occur on many hydrophobic surfaces like the surface of hydrophobic latex particles in water, or the surface of oil droplets stabilized with a non-ionic surfactant or no surfactant at all (Marinova et al. 1996).

In the presence of PVA surfactant, $\zeta$-potential of EC particles changed i.e. absolute value of $\zeta$-potential increased gradually from $\mathrm{pH} 2$ to $\mathrm{pH} 4$ and slowly from $\mathrm{pH} 4$ to $\mathrm{pH} 10$ depending in the used PVA concentration. Still, at $\mathrm{pH} 5$ for all three samples -30 $\mathrm{mV}$ was reached, which further increased with increasing the $\mathrm{pH}$. Changed $\zeta$-potential profile indicates the presence of PVA residues on the surface of the EC particles. From the $\zeta$-potential profile for all three formulations we can conclude that the higher amount of the surface trapped PVA occurred at the lowest concentration of $0.1 \mathrm{wt} \%$. By increasing the PVA concentration, the $\zeta$-potential profile become 
Fig. $10 \mathrm{pH}$ dependent zeta potential of EC particles prepared in the presence of PVA, CMC, HEC, MC$\mathrm{HMw}$ and MC-LMw at weight concentrations of $0.1 \mathrm{wt} \%$ (black line), $1 \mathrm{wt} \%$ (blue line), and $3 \mathrm{wt} \%$ (red line). (Color figure online)
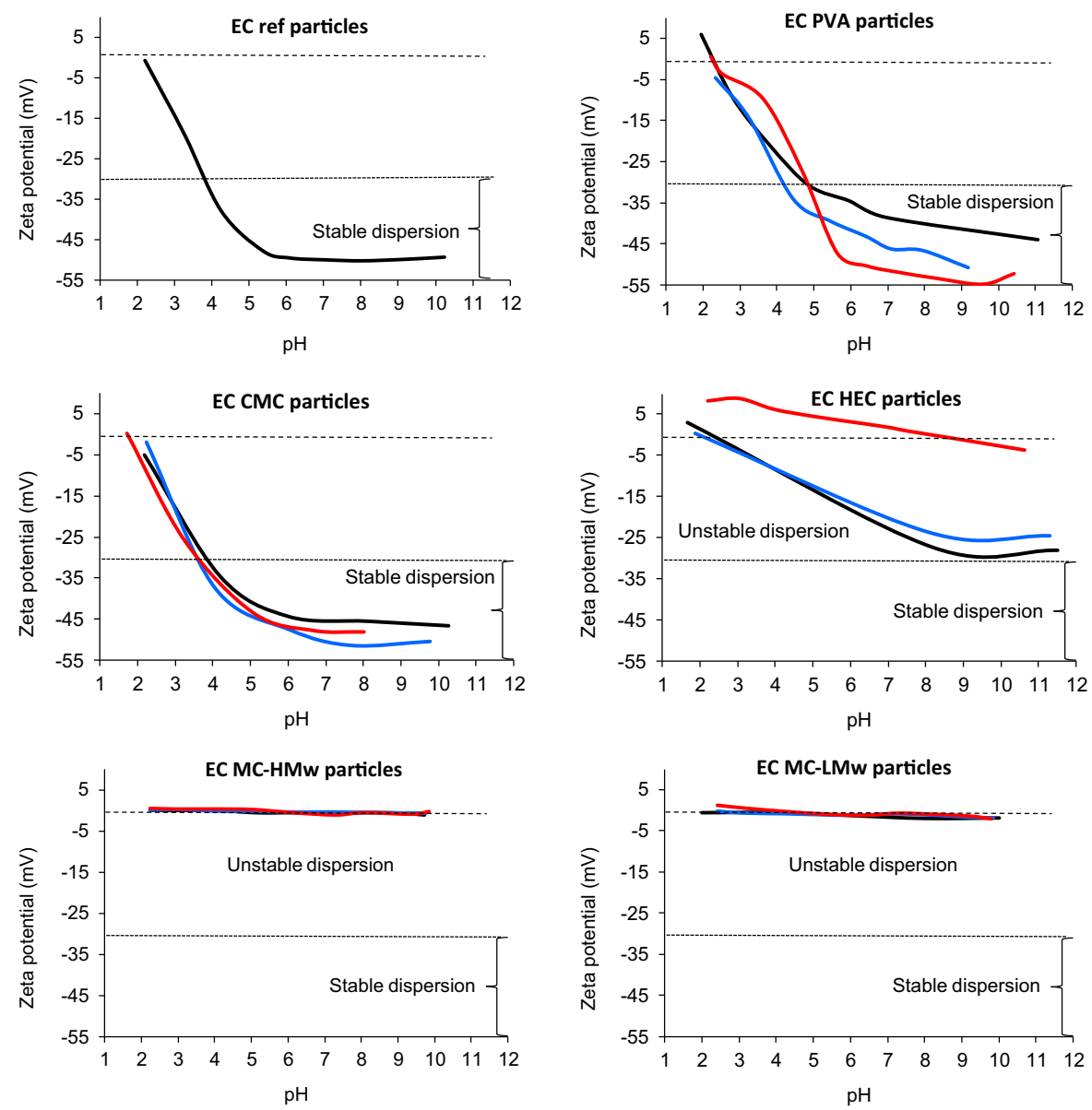

became comparable with the EC particles reference profile. As already discussed and proved by FE-SEM images in Fig. 5, the surface tension of PVA at $3.0 \mathrm{wt} \%$ was above the surface tension of water and thus, the interfacial energy between formed EC was too high and emulsion droplet coalescence occurred.

In the case of $\mathrm{CMC}$, the $\zeta$-potential profile was similar to the EC reference particles. The absolute value of $\zeta$-potential for EC particles increased gradually from $\mathrm{pH} 2$ to $\mathrm{pH} 6(-1 \mathrm{mV}$ to $-50 \mathrm{mV})$ and remained constant at $\mathrm{pH} 6$ to $\mathrm{pH} 10$ (between $-47 \mathrm{mV}$ and $-50 \mathrm{mV}$ ). Some small deviation between the CMC concentrations can be observed. For polysaccharides and PVA, various stabilization mechanisms may be involved in their actions as surfactants in the emulsion system. On the one hand, when the polymer chains interact at the droplet interface, they can induce reduction in the interfacial tension and steric stabilization. On the other hand, the non-adsorbed chains contained in the bulk solution can have an influence on the continuous phase viscosity that controls the disruption kinetics and promotes hydrodynamic stabilization.(Galindo-rodriguez et al. 2004) It can be concluded that CMC does not adsorb to the surface of the EC-organic phase droplets to a large extent because of the dominating anionic repulsion over ethyl hydrophobic attraction, but the possibility of intra- and intermolecular interaction by hydrogen bonds between the unsubstituted $\mathrm{OH}$ groups cannot be excluded. In addition, CMC influences the continuous phase viscosity and, thus, promotes hydrodynamic stabilization.

The presence of HEC surfactant, depending on the used concentration, influenced the $\zeta$-potential of EC particles to a large extent. At 0.1 and $1.0 \mathrm{wt} \%$ of the HEC, the absolute value of $\zeta$-potential slowly increased from $\mathrm{pH} 2$ to $\mathrm{pH} 8$ and remain constant between $\mathrm{pH} 8$ to $\mathrm{pH} 10$ (between $-24 \mathrm{mV}$ and 
$-28 \mathrm{mV})$. In the case of $3.0 \mathrm{wt} \%$ of HEC, $\zeta$-potential was positive, decreasing from $\mathrm{pH} 2$ to $\mathrm{pH} 9$, from 8.9 to $1.1 \mathrm{mV}$ and negative below $\mathrm{pH}$ 9, reaching $-3.6 \mathrm{mV}$ at $\mathrm{pH}$ 10. There are several reasons for positive $\zeta$-potential, which is not expected in accordance with EC and HEC molecular structure; DLS is sensitive to dynamic aggregation, aggregation, agglomeration, etc. Results presented in Fig. 7 confirmed the presence of large aggregates, which sediment out during the DLS measurements. Measured $\zeta$ potential values correspond to the smaller particles that continuously undergo dynamic aggregation and sediment. In regards to this continuous sedimentation, the net charge is continuously changing. The other reason can be due to the hydroxyl and the carboxyl groups being protonated $\left(-\mathrm{OH}_{2}{ }^{+}\right.$and $\left.-\mathrm{COOH}_{2}{ }^{+}\right)$at very low $\mathrm{pH}$. With increasing the $\mathrm{pH}$ values, hydroxyl and carboxyl groups become deprotonated $\left(-\mathrm{O}^{-}\right.$, $\mathrm{COO}^{-}$) and particles becomes negatively charged as indicated by the measured $\zeta$-potential values. In addition, a changed $\zeta$-potential profile indicates that HEC polymers chains strongly cover or interpenetrate the EC matrix, and cannot be removed during the extensive washing steps.

In the presence of methyl cellulose $\mathrm{MC}-\mathrm{HMw}$ and MC-LMw, $\zeta$-potential of EC particles drastically changed at all used concentrations. In all cases the absolute value of $\zeta$-potential decreased to zero, due the adsorbed layer of both amphiphilic methyl cellulose's, which displaced the slipping plane and reduced the measured negative $\zeta$-potential. Two important conclusions can be drawn from methyl cellulose experiments: (1) interpenetration is the mechanism proposed to explain MC-HMw and MC-LMw binding at the emulsion droplet interface, and (2) the strong interaction of both methyl celluloses at the interface leading to an irreversible adsorption of methyl cellulose at the EC particle surface. Removing the excess polymer in the final rinsing step has shown to be difficult in the case of both methyl cellulose as revealed by zeta potential measurements.

The influence of the aqueous $\mathrm{pH}$ medium was used to examine an effect on the mean hydrodynamic diameter i.e. dispersion stability and polydispersity index (PDI) for reference EC particles and EC particles dispersions, prepared in the presence of PVA (0.1 wt \%), CMC (0.1 wt \%), HEC (0.1 wt \%), $\mathrm{MC}-\mathrm{HMw} \quad(0.1 \mathrm{wt} \%)$ and MC-LMw $(3.0 \mathrm{wt} \%)$ (Fig. 11). The negative $\zeta$-potential for reference EC particles decreased gradually from $\mathrm{pH} 2$ to $\mathrm{pH} 6$ $(-1 \mathrm{mV}$ to $-50 \mathrm{mV})$ and remained constant from pH 6 to pH 10 (ca. - $50 \mathrm{mV}$ ) (Fig. 10). Accordingly, the hydrodynamic diameter slowly decreased from $\mathrm{pH}$ 2 to $\mathrm{pH} 6$ (from 1335 to $1288 \mathrm{~nm}$ ) and remained constant from $\mathrm{pH} 8$ to $\mathrm{pH} 10$ (ca. $950 \mathrm{~nm}$ ). One can suppose that the negative EC particle surface net charge origins from adsorbed $\mathrm{OH}^{-}$ions at higher $\mathrm{pHs}$, whereas at lower $\mathrm{pHs}$ the concentration of $\mathrm{OH}^{-}$is low and, thus, the increase of the hydrodynamic EC particles diameter at $\mathrm{pH} 2$ displays a hydrophobic EC particles stabilization mechanism. In addition, the PDI is increased from 0.26 at $\mathrm{pH} 6-0.62$ at $\mathrm{pH} 2$. The PDI is a dimensionless parameter that is a measure of the broadness of the size distribution. Thus, values below 0.1 can be defined as "monodisperse", i.e., they have a narrow dispersion of sizes. Values above 0.7 are considered too polydisperse for the DLS analysis (Eaton et al. 2017). From presented data we can conclude, that reference EC particles undergo relatively little dynamic aggregation in solution and are stable and monodisperse from $\mathrm{pH} 4$ to $\mathrm{pH} 10$, where PDI is below 0.3 .

In the presence of PVA the $\mathrm{pH}$ depended hydrodynamic diameter is changed. At pH 2 was to $897 \mathrm{~nm}$ with a decrease to $643 \mathrm{~nm}$ at $\mathrm{pH} 6$ and again an increase to $832 \mathrm{~nm}$ at $\mathrm{pH} 10$. Nevertheless, EC particles are considered as stable with a relative narrow size distribution (PDI from 0.1 to maximum $0.25)$.

The lowest hydrodynamic diameter was detected for particles made in the presence of CMC i.e. from $1039 \mathrm{~nm}$ at $\mathrm{pH} \mathrm{2,} \mathrm{decreasing} \mathrm{to} 397 \mathrm{~nm}$ at $\mathrm{pH} 4$ and remaining more or less constant to $\mathrm{pH} 10(317 \mathrm{~nm})$. Although the zeta potential (Fig. 10) did not drastically change, we can assume that a small amount of surface trapped CMC can influence the aggregation mechanisms. The carboxylic acid groups in aqueous medium start to dissociate above $\mathrm{pH} 4$, which means that particles in suspension tend to repel each other and the suspension is stable. Accordingly, the PDI values decreased from 0.25 to 0.19 with increasing the $\mathrm{pH}$ from 2 to 10.

The hydrodynamic diameter of particles produced in the presence of HEC slowly decreased from $\mathrm{pH} 2$ to $\mathrm{pH} 6$ (from 1784 to $890 \mathrm{~nm}$ ) and increased with increasing $\mathrm{pH}$ from $\mathrm{pH} 6$ to $\mathrm{pH} 10$ (from 890 to $1222 \mathrm{~nm}$ ). HEC is a nonionic surfactant and stable over a $\mathrm{pH}$ range between 2 and 12. The 
Fig. 11 Correlation between $\mathrm{pH}$ value, hydrodynamic diameter and polydispersity index (PDI) of reference EC and EC particles prepared in the presence of PVA $(0.1 \mathrm{wt} \%)$, CMC (0.1 wt $\%)$, HEC (0.1 wt $\%)$, MC-LMw (0.1 wt \%), and MC-HMw (3.0 wt $\%)$
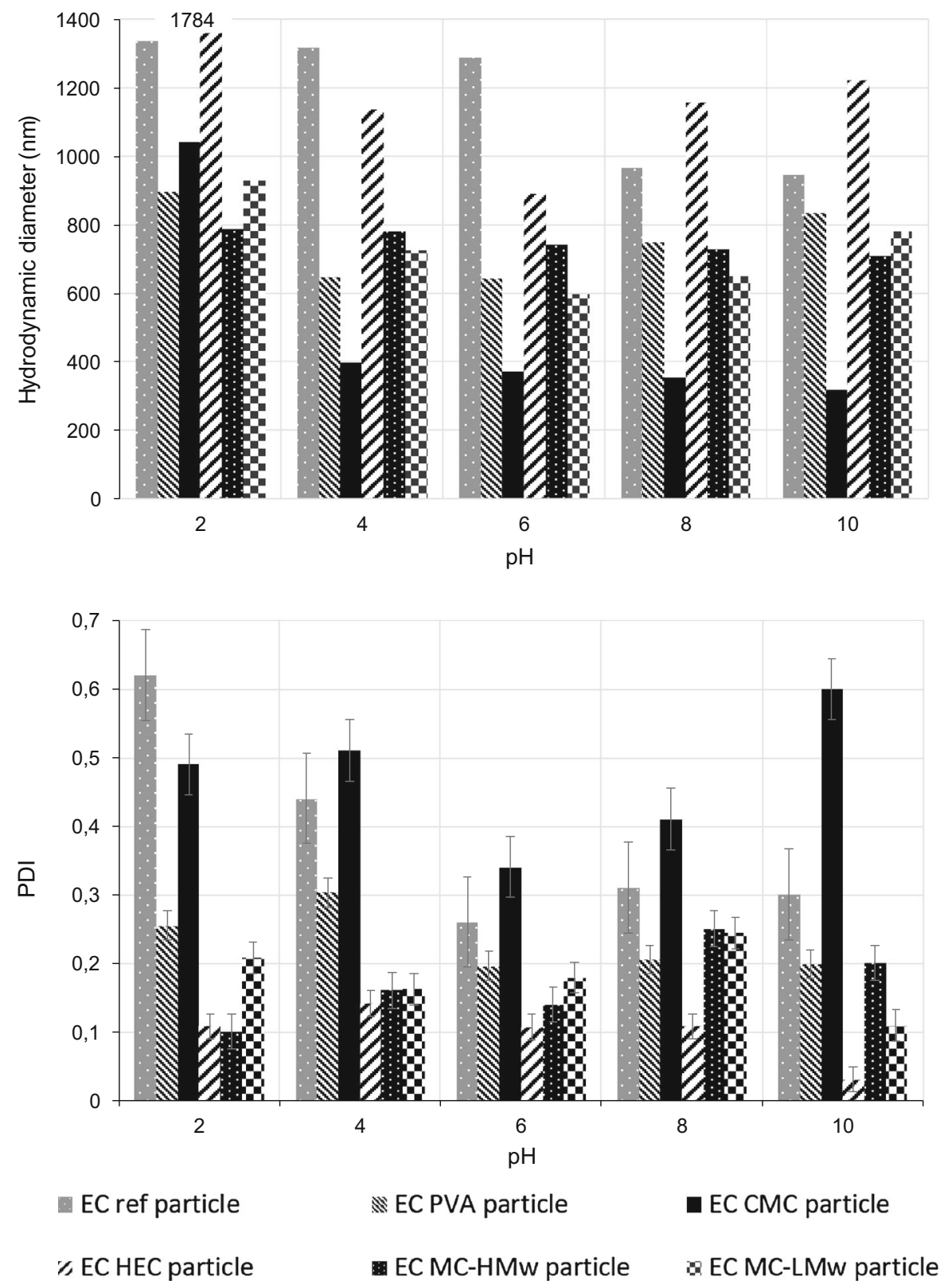

increased hydrodynamic diameter compared to EC particles stabilized with other polymers can be explained by its high water retention capacity i.e. is twice as that of methyl cellulose. PDI values are fairly low, from 0.25 at $\mathrm{pH} 2-0.19$ at $\mathrm{pH} 10$, indicating particles with a narrow size distribution over the whole tested $\mathrm{pH}$ range.

From Fig. 10 it can be observed that the $\zeta$-potential of all samples prepared with both methyl celluloses at different concentrations is close to zero. This values of zeta potentials indicate that the MC-HMw and MCLMw were not removed from the EC particles and that high particle aggregation is expected. However, from the stability test, presented in Fig. 11, we can observe that for MC-HMw the hydrodynamic diameter was between $789 \mathrm{~nm}$ at $\mathrm{pH}$ 2, $600 \mathrm{~nm}$ at pH 6 and $709 \mathrm{~nm}$ at $\mathrm{pH} 10$, demonstrating a low level of aggregation. The PDI values of EC particles, produced in the presence of MC-HMw were between 0.49 and 0.60 between $\mathrm{pH} 2$ and $\mathrm{pH}$ 10. The lowest PDI values were 
obtained for EC particles, produced in the presence of MC-LMw i.e. between 0.11 and 0.03 for $\mathrm{pH}$ between 2 and $\mathrm{pH} 10$, respectively. It is possible that in solution the EC particles dynamically aggregate and deaggregate, given the average hydrodynamic diameter is $740 \mathrm{~nm}$, which is larger than any individual particles according to the microscopy data (i.e. $169 \mathrm{~nm}$ ).

\section{ATR-FTIR measurement}

ATR-FTIR was performed to investigate the differences of hydrogen bonding patterns in EC particles. Before ATR-FTIR spectra deconvolution, the water content was traced by the absorbance band at $1635 \mathrm{~cm}^{-1}$. For all particles samples the height of the $1635 \mathrm{~cm}^{-1}$ band was reduced to zero after freezedrying, except for EC-CMC particles, where small $1635 \mathrm{~cm}^{-1}$ was still present (data not shown). Therefore, the influence of water on the intensities and positions of the bands in deconvoluted spectra of differently prepared EC particles was excluded. Further, a detailed ATR-FTIR analysis was done by band deconvolution from the background scattering, using a Gaussian function curve-fitting analysis, performed on PeakFit ${ }^{\circledR}$ v4.12 software. For confirmation of the results, the second derivative was inspected and local minima were used for the determination of the bands' positions within the region from 3700 to $3100 \mathrm{~cm}^{-1}$. Calculations were repeated until a best-fit was obtained with $\mathrm{R}^{2}>0.999$. In Fig. 12, deconvoluted spectra are shown for reference EC and particles prepared in the presence of PVA $(0.1 \mathrm{wt} \%), \mathrm{CMC}$ (0.1 wt $\%)$, HEC (0.1 wt $\%)$, MC-LMw (0.1 wt $\%)$, and MC-HMw (3.0 wt \%). The assignments for intramolecular hydrogen bonds of $\mathrm{O}(2) \mathrm{H} \cdots \mathrm{O}(6)$ and $\mathrm{O}(3) \mathrm{H} \cdots \mathrm{O}(5)$, and intermolecular hydrogen bonding of $\mathrm{O}(6) \mathrm{H} \cdots \mathrm{O}(5)$ in the cellulose crystalline structure are generally shown at $3410-3460 \mathrm{~cm}^{-1}$, $3340-3375 \mathrm{~cm}^{-1}$, and $3230-3310 \mathrm{~cm}^{-1}$, respectively (Ciolacu et al. 2010). Newly introduced functional groups i.e. $-\mathrm{CH}_{2} \mathrm{CH}_{3},-\mathrm{CH}_{2} \mathrm{COONa},-\mathrm{CH}_{2} \mathrm{CH}_{2} \mathrm{OH}$, $\mathrm{CH}_{3}$ etc. modify the initial system of hydrogen bonds, distorts the regular arrangement of cellulose chains, and changes the supramolecular structure of the polymer towards a decrease in the macro-chain ordering. In order to study the changed supramolecular structure, the ATR-FTIR absorption bands in the $\mathrm{OH}$ stretching region for each sample were deconvoluted into four IR bands with peaks between 3700 and
$3500 \mathrm{~cm}^{-1}$ assigned to hydroxyl groups, between $3600-3350$ and $3450-3250 \mathrm{~cm}^{-1}$ assigned to intramolecular hydrogen bonding and between $3350-3100 \mathrm{~cm}^{-1}$ assigned to intermolecular hydrogen bonding. EC reference particles showed a symmetric $\mathrm{OH}$ absorption band, which was attributed to two intramolecular hydrogen bonds: one between the hydroxyl/ethyl at the $\mathrm{C}(3)$ position and its neighboring ring oxygen $(\mathrm{O}(5))$ and the second between the hydroxyl/ethyl at the $\mathrm{C}(2)$ position and the ether oxygen of $\mathrm{OCH}_{2} \mathrm{CH}_{3}$ at the $\mathrm{C}(6)$ position. There are very few intermolecular hydrogen bonds and more free hydroxyl groups identified, suggesting that regular distribution of the ethyl substituents on the $C(6)$ and $\mathrm{C}(3)$ positons hindered hydrogen bonding. In the case of EC particles produced in the presence of CMC, HEC, MC-HMw and MC-LMw, the peak between 3700 and $3100 \mathrm{~cm}^{-1}$ becomes broader, indicating on an increased number of hydroxyl groups and a rearrangement of the hydrogen bonding occurring with a change of the composition. All in all, present 'free' hydroxyl groups give rise to disordered regions, where many of the $\mathrm{OH}$ and functional groups on neighboring chains are not close enough to each other to enter into a hydrogen bonding arrangement. On the other hand, the intermolecular bonding increased in the presence of surface active components, indicating an increased level of amorphous domains partly interacting by intermolecular hydrogen bonds (Kondo and Sawatari 1996).

Hydrogen bonding i.e. length and energy of the intra- and intermolecular hydrogen bonds in highly ordered regions of the cellulose structure with parallel arrangement of the cellulose chains were actively studied by Zhbankov and coworkers.(Zhbankov 1995a, b) They considered the most stable conformations of the native cellulose chains, where the bond length and hydrogen bonding energy of $\mathrm{O}(3) \mathrm{H} \cdots \mathrm{O}(5)$ is reported to be between 1.81 and $1.86 \AA$, and 11.5 and $13.2 \mathrm{~kJ} \mathrm{~mol}^{-1}$, respectively; bond length and hydrogen bonding energy of $\mathrm{O}(2) \mathrm{H} \cdots \mathrm{O}(6)$ between 1.74 and $1.91 \AA$, and 10.0 and $14.9 \mathrm{~kJ} \mathrm{~mol}^{-1}$, respectively; and bond length and hydrogen bonding energy of $\mathrm{O}(6) \mathrm{H} \cdots \mathrm{O}(3)$ between 1.82 and $1.96 \AA$, and 8.6 and $12.8 \mathrm{~kJ} \mathrm{~mol}^{-1}$, respectively. In Table 1 the hydrogenbond $(\mathrm{R})$ and hydrogen bonding energy $\left(\mathrm{kJ} \mathrm{mol}^{-1}\right)$ values obtained for reference EC particles and EC particles prepared in the presence of PVA $(0.1 \mathrm{wt} \%)$, CMC (0.1 wt \%), HEC (0.1 wt $\%)$, MC-LMw 

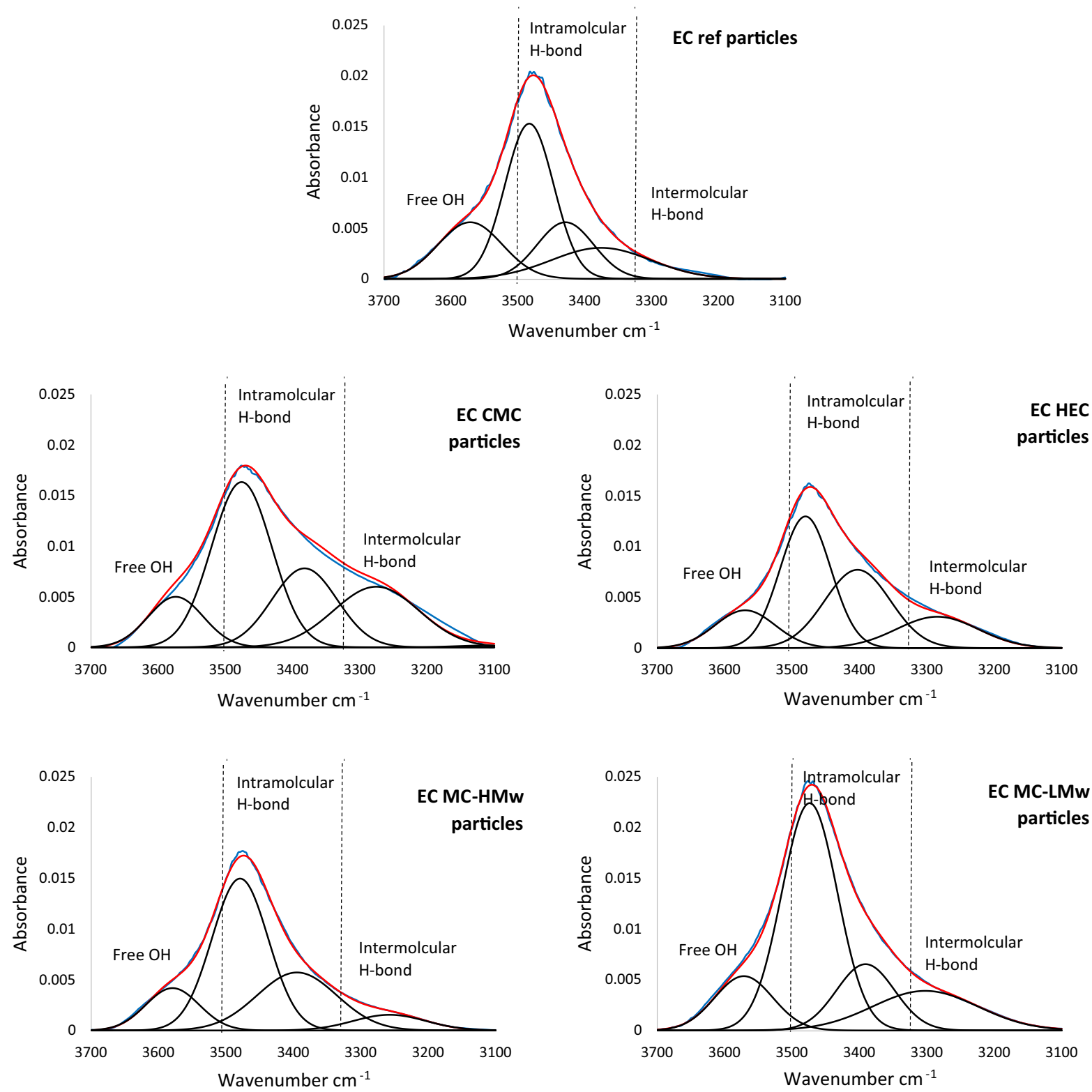

Fig. 12 Fourier self-deconvolution and the curve fitted ATRFTIR absorbance spectra in the range of 3700 and $3100 \mathrm{~cm}^{-1}$ for reference and EC particles prepared in the presence of PVA

(0.1 wt $\%)$, CMC (0.1 wt $\%)$, HEC (0.1 wt $\%)$, MC-LMw (0.1 wt $\%)$, and MC-HMw (3.0 wt $\%)$

(0.1 wt $\%$ ), and MC-HMw (3.0 wt $\%)$ are compared. Initial reference EC particles with increased hydrogen bond length of $2.796-2.820 \AA$ compared to native cellulose structure indicate on poorly ordered structure. By using surface active polysaccharides i.e. CMC, HEC, MC-HMw and MC-LMw, the hydrogen bond length decreased and new supramolecular structures of EC particles were formed, being non-

crystalline but containing more ordered cellulose chains. Of all tested surface active polysaccharides, MC-LMw yielded the shorter hydrogen bonds, which are generally the stronger, and thus the highest ordered supramolecular structure. Energy of the hydrogen bonds is correlated with the number of hydrogen bonds i.e. with increased number of hydrogen bonds, the energy is increased. This consequently influences 
Table 1 The length and energy of the intra- and intermolecular hydrogen bonds of reference EC and particles prepared in the presence of PVA (0.1 wt \%), CMC (0.1 wt\%), HEC (0.1 wt\%), MC-LMw (0.1 wt \%), and MC-HMw (3.0 wt \%)

\begin{tabular}{|c|c|c|c|c|c|c|}
\hline \multirow[t]{2}{*}{ Sample } & \multicolumn{2}{|c|}{$\begin{array}{l}\text { Intramolecular H-bond of } \\
\mathrm{O}(2) \mathrm{H} \cdots \mathrm{O}(6)\end{array}$} & \multicolumn{2}{|c|}{$\begin{array}{l}\text { Intramolecular H-bond of } \\
\mathrm{O}(3) \mathrm{H} \cdots \mathrm{O}(5)\end{array}$} & \multicolumn{2}{|c|}{$\begin{array}{l}\text { Intermolecular H-bond of } \\
\mathrm{O}(6) \mathrm{H} \cdots \mathrm{O}(3)\end{array}$} \\
\hline & $\mathrm{R} R(\AA)$ & $\mathrm{E}_{\mathrm{H}}\left(\mathrm{kJ} \mathrm{mol}^{-1}\right)$ & $\mathrm{R}(\AA)$ & $\mathrm{E}_{\mathrm{H}}\left(\mathrm{kJ} \mathrm{mol}^{-1}\right)$ & $\mathrm{R}(\AA)$ & $\mathrm{E}_{\mathrm{H}}\left(\mathrm{kJ} \mathrm{mol}^{-1}\right)$ \\
\hline EC particles & 2.820 & 1.467 & 2.808 & 2.367 & 2.796 & 3.267 \\
\hline EC CMC particles & 2.819 & 1.632 & 2.797 & 3.198 & 2.773 & 4.980 \\
\hline EC HEC particles & 2.819 & 1.501 & 2.802 & 2.784 & 2.775 & 4.769 \\
\hline EC MC-HMw particles & 2.819 & 1.663 & 2.800 & 3.060 & 2.779 & 4.355 \\
\hline EC MC-LMw particles & 2.818 & 1.663 & 2.799 & 3.016 & 2.769 & 4.499 \\
\hline
\end{tabular}

the supramolecular structure. The lowest energy of the hydrogen bonds $\left(\mathrm{E}_{\mathrm{H}}\right)$ was recorded for reference $\mathrm{EC}$, and this value increased after producing EC particles in the presence of surface active polysaccharides, indicating an increase of the number of hydrogen bonds and consequently changes in the supramolecular structure, that is, an increase in the degree of ordered domains.

\section{Conclusion}

The process emulsion solvent evaporation was currently used for the manufacture of ethyl cellulose nano-micro particles in the presence of surface active compounds. The impact of the molecular characteristics of four different surface active polysaccharides i.e. ionic-CMC, nonionic-HEC and two amphiphilicMC-HMw and MC-LMw on their ability to increase viscosity and promote depletion flocculation in aqueous EC-ethyl acetate emulsions was studied.

It was found that at the constant conditions in which the nano to micro sized particles were formed were greatly influenced by the type and the concentration of the used surface active polysaccharides. Taken together, the data obtained show the importance of the used surface active polysaccharides at defined concentration on the final nanoparticle architecture and mechanism of formation. High molecular weight polysaccharides HEC and MC-HMw at $3 \mathrm{wt} \%$ increased viscosity of the studied emulsions from 600 to 1200 times compared to the CMC and MCLMw, leading to the less favorable mixing efficiency with outcome in semi-spherical microscale particle sizes. Lower molecular CMC and MC-LMw took less space in the aqueous solvent, their hydrodynamic volume was smaller, leading to the favorable mixing efficiency with outcome of smooth spherical nano sized particles. $\zeta$-potential values of the measured EC particles prepared in the presence of different surface active polysaccharide revealed that all polysaccharides at all tested concentrations were more or less integrated into EC surface structure and changed surface properties of formed EC particles. Especially surface active were MCs, where formed EC particles were completely surface covered with MC polymers and new surface properties of the particles were designed. Surface active polysaccharide polymers interacted with EC at the molecular level and that new supramolecular structures were formed, being non-crystalline but containing some ordered cellulose chains.

Newly design nanoparticles have great potential to be used as mucosal drug delivery system. In order for nanoparticle carrier system to permeate the mucus gel layer and to be taken up by the epithelium, require controlled surface properties and surface topography. Protecting mucus gel layer has a net negative charge, thus, negative nanoparticle carrier can avoid ionic interactions with mucus and are able to permeate the mucus layer. For cell membrane adherence and subsequent effective cellular uptake rough or wrinkled surface are preferred over smooth surfaces. It was proved that cells adherent to non-smooth surfaces more firmly and durable compared to those on smooth surfaces (Liu and Tang 2017).

Acknowledgments The authors gratefully acknowledge financial supports from the European Union's Horizon 2020 research and innovation programme under Conquer projectGrant Agreement No 665172. Urška Jančič from the University 
of Maribor, is greatly acknowledged for hers support regarding the viscosity measurements.

Open Access This article is distributed under the terms of the Creative Commons Attribution 4.0 International License (http:// creativecommons.org/licenses/by/4.0/), which permits unrestricted use, distribution, and reproduction in any medium, provided you give appropriate credit to the original author(s) and the source, provide a link to the Creative Commons license, and indicate if changes were made.

\section{References}

Bizmark N, Ioannidis MA (2017) Ethyl cellulose nanoparticles at the alkane-water interface and the making of pickering emulsions. Langmuir 33:10568-10576. https://doi.org/10. 1021/acs.langmuir.7b02051

Božič M, Vivod V, Kavčič S et al (2015) New findings about the lipase acetylation of nanofibrillated cellulose using acetic anhydride as acyl donor. Carbohydr Polym 125:340-351. https://doi.org/10.1016/j.carbpol.2015.02.061

Christine V, Ponchel G (2017) Polymer nanoparticles for nanomedicines. A guide for their design. Anticancer Res 37:1544. https://doi.org/10.1007/978-3-319-41421-8

Ciolacu D, Kovac J, Kokol V (2010) The effect of the cellulosebinding domain from Clostridium cellulovorans on the supramolecular structure of cellulose fibers. Carbohydr Res 345:621-630. https://doi.org/10.1016/j.carres.2009. 12.023

Ciolacu D, Ciolacu F, Popa VI (2011) Amorphous cellulosestructure and characterization. Cellul Chem Technol 45:13-21

Coombs Obrien J, Torrente-Murciano L, Mattia D, Scott JL (2017) Continuous production of cellulose microbeads via membrane emulsification. ACS Sustain Chem Eng 5:5931-5939. https://doi.org/10.1021/acssuschemeng. $7 \mathrm{~b} 00662$

Crowley MM, Schroeder B, Fredersdorf A et al (2004) Physicochemical properties and mechanism of drug release from ethyl cellulose matrix tablets prepared by direct compression and hot-melt extrusion. Int $\mathrm{J}$ Pharm 269:509-522. https://doi.org/10.1016/j.ijpharm.2003.09. 037

Desgouilles S, Vauthier C, Bazile D et al (2003) The design of nanoparticles obtained by solvent evaporation: a comprehensive study. Langmuir 19:9504-9510. https://doi.org/10. 1021/la034999q

Eaton P, Quaresma P, Soares C et al (2017) A direct comparison of experimental methods to measure dimensions of synthetic nanoparticles. Ultramicroscopy 182:179-190. https://doi.org/10.1016/j.ultramic.2017.07.001

El-Habashy SE, Allam AN, El-Kamel AH (2016) Ethyl cellulose nanoparticles as a platform to decrease ulcerogenic potential of piroxicam: formulation and in vitro/in vivo evaluation. Int J Nanomedicine 11:2369-2380. https://doi. org/10.2147/IJN.S93354

Galindo-rodriguez S, Alle E, Fessi H, Doelker E (2004) Physicochemical parameters associated with nanoparticle formation in the salting-out, nanoprecipitation methods. Pharm Res 21:1428-1439. https://doi.org/10.1023/B: PHAM.0000036917.75634.be

Generalova AN, Sizova SV, Oleinikov VA et al (2009) Highly fluorescent ethyl cellulose nanoparticles containing embedded semiconductor nanocrystals. Colloids Surf Physicochem Eng Asp 342:59-64. https://doi.org/10.1016/ j.colsurfa.2009.04.007

Gunduz O, Ahmad Z, Stride E, Edirisinghe M (2012) Continuous generation of ethyl cellulose drug delivery nanocarriers from microbubbles. Pharm Res. https://doi.org/10. 1007/s11095-012-0865-7

Jin H, Zhou W, Cao J et al (2012) Super stable foams stabilized by colloidal ethyl cellulose particles. Soft Matter 8:2194-2205. https://doi.org/10.1039/C1SM06518A

Kargl R, Mohan T, Bračič M et al (2012) Adsorption of carboxymethyl cellulose on polymer surfaces: evidence of a specific interaction with cellulose. Langmuir 28:11440-11447. https://doi.org/10.1021/la302110a

Katikaneni PR, Upadrashta SM, Neau SH, Mitra AK (1995) Ethylcellulose matrix controlled release tablets of a watersoluble drug. Int J Pharm 123:119-125. https://doi.org/10. 1016/0378-5173(95)00060-V

Khan FZ, Sakaguchi T, Shiotsuki M et al (2006) Synthesis, characterization, and gas permeation properties of silylated derivatives of ethyl cellulose. Macromolecules 39:6025-6030. https://doi.org/10.1021/ma060601w

Kondo T, Sawatari C (1996) A fourier transform infra-red spectroscopic analysis of the character of hydrogen bonds in amorphous cellulose. Polymer (Guildf) 37:393-399. https://doi.org/10.1016/0032-3861(96)82908-9

Košak A, Laki M, Lobnik A (2015) Effects and risks of nanotechnologies and nanomaterials on environment and human health. Tekstilec 58:4-22. https://doi.org/10.14502/ Tekstilec.2015.58.4-22

Kulterer MR, Reichel VE, Kargl R et al (2012) Functional polysaccharide composite nanoparticles from cellulose acetate and potential applications. Adv Funct Mater 22:1749-1758. https://doi.org/10.1002/adfm.201102350

Liu X-Q, Tang R-Z (2017) Biological responses to nanomaterials: understanding nano-bio effects on cell behaviors. Drug Deliv 24:1-15. https://doi.org/10.1080/10717544. 2017.1375577

Marinova KG, Alargova RG, Denkov ND et al (1996) Charging of oil-water interfaces due to spontaneous adsorption of hydroxyl ions. Langmuir 12:2045-2051. https://doi.org/ 10.1021/la950928i

Mohan T, Kargl R, Tradt KE et al (2015) Antifouling coating of cellulose acetate thin films with polysaccharide multilayers. Carbohydr Polym 116:149-158. https://doi.org/10. 1016/J.CARBPOL.2014.04.068

Nasatto PL, Pignon F, Silveira JLM et al (2014) Interfacial properties of methylcelluloses: the influence of molar mass. Polymers (Basel) 6:2961-2973. https://doi.org/10. 3390/polym6122961

Nava-Arzaluz MG, Piñón-Segundo E, Ganem-Rondero A, Lechuga-Ballesteros D (2012) Single emulsion-solvent evaporation technique and modifications for the preparation of pharmaceutical polymeric nanoparticles. Recent Pat Drug Deliv Formul 6:209-223. https://doi.org/10.2174/ 187221112802652633 
Petreus O, Bubulac T, Petreus I, Cazacu G (2003) Reactions of some phosphorus compounds with cellulose dissolved in aqueous alkaline solution. J Appl Polym Sci 90:273-333. https://doi.org/10.1002/app.12532

Pimentel GC, Sederholm CH (1956) Correlation of infrared stretching frequencies and hydrogen bond distances in crystals. J Chem Phys 24:639-641. https://doi.org/10. 1063/1.1742588

Rajabi-Siahboomi AR, Mehta RY, Ambudkar V et al (2017) Ethylcellulose applications in multiparticulate systems. Multiparticulate Drug Delivery. Springer, New York, pp 267-299

Saravanakumar G, Jo D-G, Park JH (2012) Polysaccharidebased nanoparticles: a versatile platform for drug delivery and biomedical imaging. Curr Med Chem 19:3212-3229. https://doi.org/10.2174/092986712800784658

Spernarth L, Magdassi S (2007) Preparation of ethyl cellulose nanoparticles from nano-emulsion obtained by inversion at constant temperature. Micro Nano Lett 2:90-95. https:// doi.org/10.1049/mnl:20070040

Urbán-Morlán Z, Mendoza-Elvira SE, Hernández-Cerón RS et al (2015) Preparation of ethyl cellulose nanoparticles by Solvent-Displacement using the conventional method and a recirculation system. J Mex Chem Soc 59:173-180. https://doi.org/10.1080/10837450600940824

Vanderhoff JW, El-Aasser MS, Ugelstad J (1978) Polymer emulsification process. Patient number US4177177 A

Veeger M, Wollenweber U, Hemming M (2013) Essentially water-free personal cleanser containing ethyl cellulose. Patien number US9155692 B2 Deb Ip Lim

Wachsmann P, Lamprecht A (2015) Ethylcellulose nanoparticles with bimodal size distribution as precursors for the production of very small nanoparticles. Drug Dev Ind Pharm 41:1165-1171. https://doi.org/10.3109/03639045. 2014.935393

Wondraczek H, Petzold-Welcke K, Fardim P, Heinze T (2013) Nanoparticles from conventional cellulose esters: evaluation of preparation methods. Cellulose 20:751-760. https:// doi.org/10.1007/s10570-013-9874-x

Zhbankov RG (1995a) Infrared spectra of cellulose and its derivatives. Springer, Boston

Zhbankov RG (1995b) The possibilities of the infrared spectroscopic method for investigation of the properties of cellulose and its derivatives. Infrared spectra of cellulose and its derivatives. Springer, Boston, pp 167-186 